\title{
Álgebras y tramas en el cálculo de riesgos
}

\author{
Elías Sevilla Casas \\ Profesor titular de la facultad de ciencias sociales \\ Y ECONÓMICAS, UniVERSIDAd DEL VALLE, CALI \\ esevilla@telesat.com.co \\ Teresita Sevilla Peñuela \\ Candidata a doctorado en sociología (Queen's University, Belfast)
}

\section{Resumen}

M ediante la metáfora borgeana de “el Álgebra y el fuego" Se describen y comentan los modos como epidemiólogos y salubristas, por un lado, y antropólogos y sociólogos, por otro, trabajan, en frío, la noción de riesgo para la salud y la vida. Con ejemplos se expone la complejidad de las tramas de riesgo que construyen los quejuegan, en caliente, con la salud y la vida de otros, así como la naturaleza de las álgebras que aplican a su situación los que corren los riesgos y sufren las consecuencias de sus decisiones. Estas consideraciones se tratan desde un punto de vista metodológi co y técnico, centrado en los diseños especial izados de los estudios sobre riesgos.

PALABRAS CLAVE: antropología de la sal ud, antropología médica, epidemiología, estudios de riesgo, salud pública.

\begin{abstract}
Sing Borges' metaphor of "algebra and fiRe" We describe and discuss the ways in which epidemiologists and public health officials, on the one hand, and anthropologists and sociologists, on the other, construct in cold blood the notion of health and life risks. Additionally, the complexity of risk wefts (tramas) constructed by people who pursue, while in action, their own interests at the cost of others' risks are described using detailed examples, as well as the algebras applied to their own situation by those who take risks and suffer the consequences of those decisions. All these considerations are made from a technical and methodological point of view that centers on deriving expert designs for studying risks.
\end{abstract}

KEY WORDS: Anthropology of health, medical anthropology, epidemiology, risk studies, public health. 
Para la razón, para el entendimiento lógico, esta variedad de valores puede constituir un escándalo, no así para los sueños que tienen su álgebra singular y secreta, y en cuyo ambiguo territorio una cosa puede ser muchas.

JoRge LUIS Borges, "Nathaniel Hawthorne"

\section{NTRODUCCIÓN*}

5 L ASUNTO DE LOS RIESGOS QUE CORREMOS LOS HUMANOS, ESPECÍFICAmente los que afectan la vida y la salud, ha adquirido creciente importancia para los expertos que los estudian y los miden y para los que juegan con ellos, es decir, los que "juegan con candela". Éstos lo hacen, bien por intereses exógenos, bien por el solo gusto de jugar, de tener experiencias extremas, "de alta adrenalina", que -se piensa- dan picante a la vida que de otro modo resultaría muy sosa. Cuando el daño ocurre, el comentario común es el fatalista "shit happens" que respondió un backpacker ${ }^{1}$ europeo al ser interrogado por la antropóloga Catherine Palmer (2002) poco después de un desastre de X-Sports en Interlaken (Suiza); el joven entrevistado esperaba su turno para "la experiencia de su vida": allí mismo, en el fatídico circuito de canotaje de al to riesgo. Este "shit happens" puede tomarse como una racionalización

* En sus varias etapas de producción, el presente artículo se benefició de los comentarios de las siguientes personas: epidemiólogas Lyda 0 sorio MD, PhD (Londres) y Katia Feliciano MD, PhD (Rio de Janeiro); antropólogo Manuel Sevilla PhD (C; Toronto); dos amables lectores de la Revista Colombiana de Antropología. 0 bviamente, la responsabilidad final de lo escrito es de los autores.

1 Términos intraducibles. Aproximadamente: "la mierda ocurre", con énfasis sobre la contingencia de su aparición al azar, incontrolable, como una maldición en el curso de la vida. Backpacker es el turista o trashumante escotero, que sólo lleva su morral. que cubre, no propiamente de "shit" pero sí de (auto)engaño, los riesgos quelos X-Sports esconden para los ávidos incautos.

En el contexto descrito, el riesgo como imagen pública y privada se ve transformado por las condiciones mismas de la comercialización o de la banalización a que se le somete. El juego con "este mecho" de vida o de salud adquiere visos de atracción irresistible, de experiencia extrema y positiva, cuando no de oportunidad desconocida para lograr metas estratégicas en los proyectos personales o corporativos. Para la salud pública, lo preocupante de esta transformación es que, bajo el manto de la imagen construida, el peligroy el daño potencial semantienen intactos, cuando no aumentan 
extraordinariamente: las fuerzas no humanas -presentes en los rápi dos de un río crecido, en la cima imposible de escalar, en el motor de combustión conducido a altísima velocidad, en el intercambio sexual de fluidos corporales o en la bala de sicario que hace "un trabajito"...-, simplemente no obedecen al juego simbólico con que lo recubrimos los humanos. Son mortales o dañinas porque son ciegas a los símbolos.

La sociedad contemporánea tiene expertos que calculan los riesgos en frío; son ellos economistas, geógrafos, criminólogos, juristas, ingenieros y otros más, según los tipos de peligro que acechan a la humanidad. En el presente artículo nos centraremos en dos conjuntos de expertos, cuyos estudios sirven inmediatamente a la salud pública: Ios epidemi ólogos y los sociólogos/ antropólogos. Contrastaremos aquí la tradición epidemiológica que está detrás del Ilamado "enfoque de riesgo" en los estudios de salud pública con la tradición sociológica y antropológica que ha avanzado recientemente hasta hablar, a boca llena, de "la sociedad del riesgo". Conexos con los primeros, por su énfasis en individuos enfermos, están los promotores de la medicina basada en evidencia, tan de moda hoy entre los médicos que desean salirse de rutinas. Conexos con los segundos, por su énfasis en poblaciones no en individuos, están los que si guen la "estrategia poblacional" propuesta por Geoffrey Rose (Rose, 1985 1992) y que por lo general se inscriben en la línea de trabajo Ilamada epidemiología social.

Como tenemos la convicción de queen estos campos especializados de la investigación y cál culo en frío de los riesgos para la salud y la vida se trabaja con ál gebras especializadas divergentes, mutuamente desconocidas, o por lo menos rara vez coordinadas, haremos reflexiones que faciliten la convergencia en una misma mesa de trabajo. Escribimos, como lo supone la Revista, pensando ante todo en la comunidad antropológica y en sus vecinos inmediatos de las ciencias sociales, pero con el ánimo de que también nos lean los colegas de las ciencias de la salud.

La exposición que pretendemos iniciará con una sección dedicada a presentar la metáfora borgeana del ál gebra. Hablaremos luego del ál gebra fría de los epidemiólogos y de los diseños basados en ella. Presentaremos enseguida una sección dedicada al álgebra en caliente de los que juegan con el riesgo de otros como pretexto o instrumento de sus propios intereses; 
un ejemplo complejo y detallado tomado de la historia de la malaria permi tirá apreciar mejor lo que pretendemos decir. Luego trabajaremos el álgebra de los que juegan "con candela" a riesgo de su propio daño. En la sección siguiente nos referiremos a las propuestas conceptuales antropológicas y sociológicas, esta vez frías, sobre la noción de riesgo para, por último, detenernos en consideraciones de orden técnico sobre diseños y modos de trabajo que permitan la cooperación futura entre las disciplinas mencionadas, basados en la idea de que las álgebras deben versar sobre las tramas vivas en que se esconden esos riesgos.

Estas disciplinas han teni do entre sí una actitud que al gunos autores, hablando desde la antropología médica, han tildado de "desatención benigna" (Trostle y Sommerfeld, 1996). A nuestro juicio, esta actitud debe ser convertida en cooperación activa y agradable. Por ello, para ser prácticos, nos detenemos en asuntos técnicos, como los diseños y modos de inferencia, que podrían dar paso, rápidamente, a proyectos compartidos, que se están necesitando. Quienes se beneficiarán, a más de las disciplinas en cuestión, son, ante todo, los sujetos humanos de la salud pública, individuos y colectivos, que corren los riesgos y sufren sus eventual es consecuencias.

\section{Álgebras y fuego en la palabra de Borges}

omo hablamos de Álgebras, es preciso presentar la metáfora y su fuente. Proviene de Jorge Luis Borges, que la tiene como aspecto casi obsesi vo en varias de sus obras. Ál gebra setoma en Borges y aquí, debido al préstamo, como una fórmula intelectual que representa los fenómenos de la vida. Está hecha de símbolos susceptibles de cál culo abstracto, aquel que simplifica y generaliza el pal pitar concreto y bastante impredecible en que se desenvuelve la vida humana cuando se la mira en la riqueza de sus tramas o situaciones singulares. En palabras del poeta Louis Armand, álgebra es un conjunto de palabras vacías que funcionan como máquinas de información para conjugar orden y desorden e introducir información en donde antes no la había. 
En Historia de la eternidad, y en un par de obras más, Borges opone el álgebra al fuego, como metáfora binaria dela "complejidad de nuestro ser"; fuego por el pal pitar de la vida y álgebra por el esfuerzo mental de aprehenderla en model os pre verbales y en discursos, los de los legos y los de los expertos. Por ello hablamos de álgebras en frío y en caliente: las primeras están, por lo abstractas, alejadas del fuego de la situación concreta en que se juega al riesgo; y las segundas, por lo referidas a lo concreto, están metidas en el fuego, que a veces las consume. Habrá oportunidad de elaborar, Ilevados de la mano lúcida del maestro ciego, las implicaciones de esta metáfora hermosa.

La frase del epígrafe está tomada de un estudio que Borges hace de la obra de Nathaniel Hawthorne (Borges [1949] 1974: 670685) y, específicamente, del pasaje de The Marble Faun en que los protagonistas hablan de la grieta, una de las bocas "del abismo de oscuridad que está debajo de nosotros, en todas partes. La sustancia más firme de la fel icidad de los hombres [dice un protagonista] es una lámina interpuesta sobre ese abismo, y que mantiene nuestro mundo ilusorio; no se requiere un terremoto para romperla; basta poner el pie. Hay que pisar con mucho cuidado". Esa lámi na interpuesta, "Ia sustancia más firme de la felicidad de los hombres", está hecha de las ál gebras que traducen I os riesgos a proposiciones, meramente descriptivas -sin pretensiones epistémi cas o crítico-reflexivas- en el caso de las versiones de los legos; o redescriptivas -elaboradas en fórmulas más o menos abstractas- en el caso de los expertos en el cál culo o apreciación de los riesgos, como son los expertos, los epidemiólogos y antropólogos/sociólogos a que nos estamos refiriendo.

Dejemos por ahora las ál gebras varias para mirar la grieta. Borges dice que ella

es demasiadas cosas. En el curso de un solo párrafo es la grieta de quehablan los historiadores latinos y también es la boca del Infierno 'con vagos monstruos y con caras atroces' y también es el horror esencial de la vida humana y también es el Tiempo, que devora estatuas y ejércitos, y también es la Eternidad que encierra los tiempos. Es un símbolo múltiple, un símbolo capaz de muchos val ores, acaso incompatibles (Borges, 1974: 683).

Escojamos, para fines del presente argumento, una cosa de las muchas que es la grieta: "el horror esencial de la vida humana", y 
dentro de ella delimitemos el área de interés de la salud públi$\mathrm{ca}$, expresada en tasas de morbilidad y mortalidad. Esos valores cálidos, nos dice Borges en el epígrafe, son un escándalo para la razón abstracta y lógica finamente representada por la razón epidemiológica que bosquejaremos enseguida. Las ál gebras especial izadas hacen cál culos muy finos o apreciaciones muy matizadas, pero se detienen -no puede ser de otro modo por ser racionalistas, por pretender ser científico-objetivistas, por trabajar sól o números, por olvidarse de las tramas- frente al "fuego" que arde en la grieta.

\section{EL ÁlgEBRA DEL RIESGO EN LA TRADICIÓN EPIDEMIOLÓGICA Y MÉDICA}

UANDO haCia 1996 trabajábamos en CALI eXaminando las Campañas de salud pública a favor de la protección de las trabajadoras sexuales del centro de la ciudad frente al $\mathrm{VIH} / \mathrm{sida}$ mediante el uso sistemático del condón, impulsado por ellas entre los clientes, nos encontramos con indicios de una paradoja que ya había sido evidente en las campañas de "Condón 100\%" de Tailandia en 1996: aunque las tasas de uso del condón en las relaciones de comercio sexual ascendían, hasta casi Ilegar a la meta propuesta, la de infecci ones se mantenía establey, a veces, en franco ascenso. Esta situación parecía inexplicable para un razonami ento epi demiológi co si mple que establ ecía esta secuencia "causal": virus $\rightarrow$ condón $\rightarrow$ no infección. Aun descartando los "errores" usual es deestimación atribuibles a fall las del condón, fallas en su uso y otros errores similares, no había explicación para la "no transitividad" -como la llamamos entonces- entre la solución del condón y la prevención poblacional de la infección por VIH. Explorando más a fondo encontramos que en Cali estas damas efectivamente procuraban, y en ocasiones lograban, alta protección con los clientes comerciales, es decir, practicaban una lógi ca de barrera, que estaba muy acorde con la lógica general de establecer barreras entre el las y esos seres extraños llamados clientes. Más aún, el uso del condón se había convertido en signo de distinción entre las instituciones comerciales dedicadas al servicio sexual. Sin embargo, en su vida de doble fondo -eran "mujeres públicas" durante unas 


\section{Revista Colombiana \\ de Antropología

horas y "señoras" en su vida privada²- no se protegían con sus "clientes especiales", que resultaban ser sus novios o amantes ocasionales, casi siempre procedentes del mismo "grupo deriesgo" que los cl ientes ordinarios (Sevilla y Martínez, 1997). En esta lógi ca, ilógi ca para un epidemi ól ogo tradicional, radicaba el problema de la inconsistencia de las tasas.

Entramos con este ejemplo a tratar el asunto del ál gebra epidemiológica, porque la epidemia del VIH/sida en su complejísimo espectro -que va desde los virus y el sistema inmune hasta los elaborados juegos simbólicos de la vida amorosa, por una parte, y por otra hasta los subyacentes intereses económicos y de prestigio- permite ver, en primer lugar, la ingeniosidad epidemiológica en su razonamiento fulgurante, que concluyó rápi damente con la identificación del "agente causal" natural y sus efectos so-

2. La situación resultó mucho más complicada en otras modalidades de los amores comerciales, pues las más recientes ya no establecen este desdoblamiento entre "mujer pública" y "persona privada", ni siquiera acuden al cambio de nombre, de tipo de vestido y porte (hexis) personal. Este "servicio personal" se integra dentro de un proyecto de vida personal, y de negocios, en que el sexo eventual y el acompañamiento en el uso de drogas y en otros eventos no requiere del desdoblamiento (Sevilla et al., 2003 205234). bre el sistema inmune de los seres humanos. En segundo lugar permite captar el complemento simbólico y social de la historia, ya anunciado en el párrafo anterior, que se trabajará en una sección posterior.

En una revisión reciente de la trayectoria de trabajos sobre el $\mathrm{VIH} /$ sida (Delor y Hubert, 2000) se han identificado tres etapas, dos de las cual es giran al rededor de la noción epidemi ológica de "riesgo", y la tercera la desborda para acudir a la noción más compleja e incluyente de vulnerabilidad como construcción social y simbólica del riesgo. Nos detenemos en las dos primeras; a la tercera volveremos en las secciones subsiguientes.

A comienzos de la década de 1980, cuando aún no se conocía bien la naturaleza infecciosa del fenómeno, predominó la idea de grupos de riesgo -"homosexual es", "haitianos"...- de los que se decía que portaban el mal, con las consecuencias lamentables de estigmatización y exclusión, justificadas como medios necesarios para proteger al resto de la humanidad. El razonamiento era sencillo: al go deben tener esos grupos porque en ellos predomina el mal; y como no sabemos qué es, se deben aislar.

Luego, en los años 1990, cuando se identificó el agente viral, se habló de comportamientos de riesgo -"sexo anal no protegi do", 
"promiscuidad heterosexual"...-. Ya con un agente infeccioso identificado como "el culpable" en la cadena causal, se buscaron los factores de riesgo, de los cuales los decisivos cayeron casi todos en el muy complejo campo de las prácticas sexuales: la única forma de contener la epidemia era una campaña amplísima e ingeniosa de información y motivación para que esos factores, concretamente esos comportamientos riesgosos, fueran erradicados. Se creía entonces en la erradicación del mal porque se aceptaba que los seres humanos -a estas al turas de ambos sexos y de todas las razas y latitudes, pues se reconoció que el virus actuaba indiferenciadamente- eran lo suficientemente racionales para no jugar con su vida.

La antropol ogía fue una de las primeras disciplinas en mostrar que una cosa era responder positiva y verbalmente a una campaña informativa y motivadora -mediante encuestas pre y pos que florecieron por todas partes anunciando soluciones-, y otra actuar en consecuencia y en cal iente (Schoepf, 2002: 342343). Más aún, como en el caso de Cali y Tailandia, se hizo ver que incluso el cumplimiento de la meta de $100 \%$ condón con los clientes de servicios sexual es no producía los efectos esperados. Había en todo esto una inconsecuencia de facto, porque las tasas de infección, enfermedad y muerte seguían en ascenso, a pesar de los éxitos de las encuestas y de las campañas de uso del condón. En 1998 escribimos una ponencia para una consulta de expertos nacionales de Colombia sobre el control del $\mathrm{VIH} / \mathrm{si}$ da en que se hacía énfasis sobre lo que denomi namos intransitividad entre los resultados epidemi ológi cos especializados y las actuaciones preventivas de las poblaciones en riesgo (Sevilla, 1998). Algo andaba mal, porque no había efecto en las tasas de infección, a pesar de los ingentes esfuerzos por informar y motivar a los individuos de los "grupos de riesgo" respecto de los factores identificados. Y al go sigue andando mal: la información de Onusida (Unaids, 2003) nos dice que las tasas de infección y de muerte se mantienen en ascenso constante, y que en el mundo de 2003 hubo cerca de cinco millones de casos nuevos que se sumaron, a fines de ese año, a los cuarenta millones de personas que ya vivían con la infección. La epidemi ología social ha tomado cartas en el asunto para atender no sólo los aspectos biomédicos sino, y sobre todo, a los poderosos aspectos culturales, sociales y económicos que se encuentran implicados (Pundstone, Stranthdee y Cel entano, 2004). 


\section{Revista Colombiana \\ de Antropología

Veamos ahora de cerca, siguiendo a Rothman (2002: 24-25), el típico razonamiento epidemi ol ógico tradicional al rededor del riesgo: éste es un valor relativo, más exactamente una proporción promedia -de incidencia, Ilamada también tasa- que se aplica a un conjunto de personas a las que se ha hecho seguimiento durante un periodo de tiempo. La proporción (tasa) resulta de dividir el número de casos positivos nuevos-quesufren el daño- por la población de referencia, en el periodo en cuestión. Por lo general, la proporción (tasa) de incidencia se aplica a poblaciones, porquesu origen es colectivo; cuando seaplica a un individuo se denomina riesgo, que se interpreta como la probabilidad que esa persona, por pertenecer al grupo al cual se ha hecho seguimiento, tiene de tener el daño. Es preciso notar que aun cuando el origen de la proporción (tasa) de incidencia es poblacional o colectivo, la aplicación de la noción de riesgo en su versión individual se ha generalizado en salud pública, en consonancia con la preferencia por el "individualismo biomédico" (Fee y Krieger, 1993) que ha predominado en el pensami ento epi demiológi co y sal ubrista. Esta preferencia se concreta en la idea muy divulgada del "enfoque de riesgo" (Organización Panamericana de la Salud, 1986) y en su aplicación práctica, que atiende a los individuos que están "en al to riesgo". Esta dominancia del individualismo biomédico es una especificación, para el campo de la salud, del individualismo metodológico generalizado, cuya crítica ha hecho muy bien Mary Douglas, antropól oga experta en las dimensiones culturales de los riesgos (Douglas, 1992: passim).

Frentea esta tradición epi demiológica-individual ista hay una salvedad importantísima, procedente de la misma epidemiología. Hace veinte años, en un artículo crucial el epidemiólogo británico Geoffrey Rose (1985) Ilamó la atención sobre las implicaciones de esta dominancia: demostró que el tratamiento de "al to riesgo", centrado en los individuos, es paliativo, mientras que el tratamiento centrado en la población es radical, porque ataca las causas mismas del problema, dado que los determinantes de la salud individual son diferentes de los de la salud poblacional (véase Rose, 1992). La epidemiología social ha tomado esta bandera y está al frente de la campaña que impulsa la transición desde una ciencia de la salud centrada exclusivamente en los "factores de riesgo" hacia una que, sin negar las bondades de este enfoque para ciertos propósitos, identifique y 
atienda a los patrones que toma la ocurrencia de las enfermedades en las poblaciones (Koopman, 1996) ${ }^{3}$.

De manera por demás esquemática, detengámonos en al gunos aspectos técnicos: el val or relativo que está en la base del riesgo en su versión epidemiológica se calcula en las dos formas clásicas refinadas, el diseño de cohortes y el de casos y controles. Estos dos diseños, junto con la encuesta transversal, forman el conjunto

3 Sobre esta tendencia social y poblacional de la epidemiología reciente, véase el número completo dedicado a la materia por Epidemiologic Reviews, 26 de 2004. de diseños denominados observacionales, por cuanto se hacen en situaciones ordinarias de la vida, no en laboratorios, y los investigadores no intervienen en los proce-

sos estudiados. Los estudios experimental es se real izan mediante intervención del investigador en situaciones controladas (laboratorios), sea con muestras al eatorias-el Gold Standard- sea sin ellas (Grimes y Schulz, 2002) (véase la figura 1).

\section{FIGURA 1}

TIPOS DE ESTUDIOS EN EPIDEMIOLOGÍA

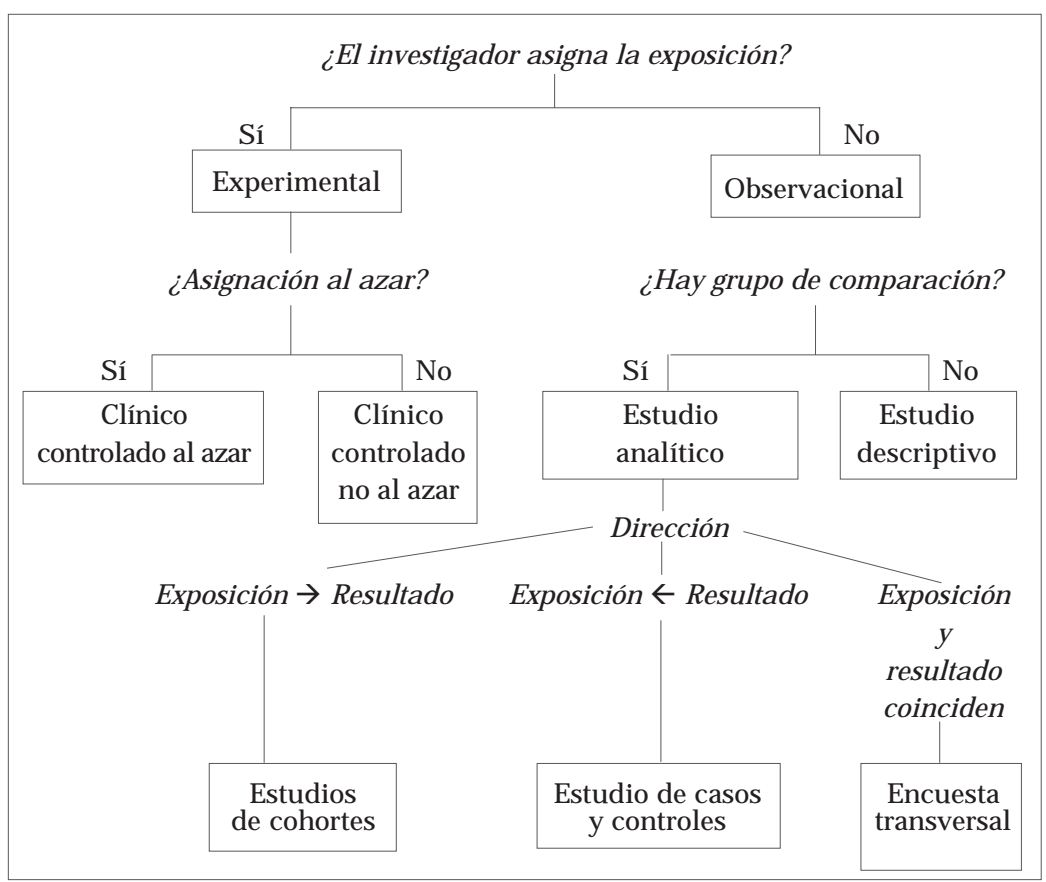

Fuente: Grimes y Shulz, 200348. 
En la primera forma observacional, Ilamada también prospectiva, se asignan los sujetos humanos del estudio a dos grupos, Ilamados cohortes, de los cuales uno se "expone" al agente o factor del que se sospecha la responsabilidad, y el otro no; luego decierto tiempo se comparan los resultados, cuando aparezca el mal. La razón entre la proporción de infectados entre los expuestos y la proporción entre los no expuestos al presunto agente responsable del daño se denomina "riesgo relativo" (RR): si la razón es 10 -o menos-, el "factor" sospechoso es eximido de responsabilidad; si es mayor que 10, el "factor" -o variable independiente- es condenado, con una responsabilidad que es proporcional a la distancia que adquiere el RR con respecto al 10. Si el RR es inferior a 10, el "factor de riesgo" seconvierteen "factor protector" frenteal daño en cuestión, con responsabilidad análoga y con una fuerza que crece a medida que la cifra se acerca al 0.

La segunda forma clásica, "casos y controles", Ilamada también retrospectiva, es la más frecuente en estudios con humanos, no sól o por razones éticas sino por motivos prácticos, tal es como la escasez relativa de casos con daño frente a la población total de referencia, o la lentitud del proceso de aparición del daño. En este diseño se toma un conjunto de casos con daño ya ocasionado, que se constituyen en el grupo de estudio; se le buscan individuos con no-daño y con ellos se constituye el grupo testigo o de control; se reconstruye la historia y se identifican los rasgos en que difieren los dos grupos comparados. Los rasgos que de manera consistente y exclusiva marcan a los que tienen el daño se denominan "factores de riesgo". La medida se denomina en inglés Odds ratio (OR), o "razón del producto cruzado" de una tabla de $2 \times 2$. La interpretación del OR es similar a la de RR con respecto al 10; sin embargo, el OR se interpreta como la probabilidad de tener el "factor de riesgo" dado que se tiene el daño.

Los otros tipos deestudio observacional, quetambién se usan en epidemi ología, sirven para hacer exploraciones iniciales -estudio descriptivo-, o para establecer tasas de prevalencias del daño y "factores de riesgo" en grupos poblacional es -estudios transversales-. La primera fase del estudio del fenómeno VIH/sida arriba mencionada se basó en estudios transversales que produjeron prevalencias; este tipo de estudio usualmente no permite concluir sobre el riesgo propiamente dicho, a no ser que los "factores de riesgo" hayan sido identificados y se desee conocer su ocurrencia en un punto del tiempo. 
Por su base innegableen materiales seriados y por su trabajo en el modelajenumérico, la epidemiología hasido definidatambién como la ciencia del conteo (Kawachi, 2002). Es otro modo de entender la venerable definición tradicional, propuesta al inicio del texto clásico de McMahon y Pugh (1970): "el estudio de la distribución y determinantes dela frecuencia de enfermedades". Como la computación estadística y la sofisticación de los diseños de investigación de cohortes y de casos-y-controles ha avanzado mucho, es posible hoy trabajar a la vez con varios candidatos a "factores" -de riesgo o protectores-. En el estudio de casos y controles es posible introducir observaciones en varios tiempos para asemejarse un poco al estudio prospectivo. La regresión logística es la manera más común de producir datos equival entes al Odds ratio (o RR); es una regresión múltiple en que la variable dependiente tiene valor dicotómico. Este método multivariado permite distribuir entre varios "factores" la "responsabilidad" presunta por un daño, objeto de estudio. Más aún, hay estudios que trabajan combinadamente con varios factores de riesgo y varios protectores.

Por ejemplo, un costosísimo estudio en Estados Unidos (Scal, Ireland y Borowsky, 2003) que toca un asunto muy preocupante también en salud pública, la iniciación del tabaquismo en adolescentes, entrevistó en un primer momento a 20.145 adolescentes escolares, y de ellos un año después a 14.738, a más de entrevistar a un número análogo de padres y maestros. El resultado de complejos anál isis logísticos determi nó que entre los factores de riesgo para el inicio de fumar estaban -por orden de importancia cuya medición aquí omitimos- el uso dealcohol, demarihuana, dedrogas ilícitas, el tener sexo y amigos que fuman; entre los factores protectores sobresalieron tener buenas calificaciones escolares y una familia unida. Los investigadores concluyeron que "Ios esfuerzos preventivos deben enfocar la reducción de los factores de riesgo y la promoción de los factores protectores en los individuos, las familias, los grupos de pares y la comunidad [...]".

Las poderosas herramientas analíticas observacionales, estudio de cohortes y estudio de casos y controles, se diseñaron inicialmente para identificar agentes dañinos y evaluar el tamaño rel ativo del riesgo a que están expuestas las personas. De la epi demiología pasaron a la sal ud públ ica como base científica para organizar campañas de todo orden que, como se vio, están organizadas, por lo general, al rededor del "enfoque de riesgo" con su sesgo individual ista. 
Poco a poco, la noción epidemi ológica de riesgo, y los modelos de estudio de ella derivados, pasaron desde las observaciones en campo abierto al mucho más control ado y aséptico de la clínica. Surgió entonces la "epi demiología clínica", con la idea de aplicar el razonamiento epidemiológico a los procesos diagnóstico, pronóstico y terapia de manera mucho más controlada, porque allí era posible lo que resultaba imposible en los ambientes cotidianos de la vida ordinaria. En la clínica, sobre todo en el campo farmacológico, pudo darse aplicación, finalmente, al Gold Standard del experimento, en la forma del estudio clínico controlado y al azar (Rothman, 2002: 198-217). Este es el model o que se utiliza, por ejemplo, para probar la eficacia de un tratami ento determinado de malaria; de su efectividad -en la vida real - hablaremos luego.

De la mano de la epidemiología clínica surgió a inicios de la década de 1990 como "gran novedad" la medicina basada en la evidencia (MBE). No es el momento de resumir las posiciones encontradas que la MBE ha suscitado dentro y fuera de la medicina y dela salud pública (Mykhal ovskiy y Weir, 2004), ni de hablar dela expansión que ha tenido la "moda BE": este estilo de trabajo ha tenido tal acogida en variados campos institucionalizados, aun fuera de la salud pública, que algún autor ingenioso habló de su banalización, porque, según dice, llegamos a "una época en que todo es BE". (El lector interesado puede visitar la internet en donde hay abundancia de referencias, y de ofertas de autoformación en MBE, incluso algunas que son casi for dummies -como vimos en alguna ocasión un resumen del Ulysses de Joyce también for dummies, es decir, para personajes que, caritativamente, pueden llamarse "de mente simplificada").

Reduciéndonos ala cuestión de la concepción de riesgo, que nos concierne en este artículo, basta decir que, viéndolo en una perspectiva histórica de siglos, y siendo rigurosos en cuanto a los procesos del juicio científico ${ }^{4}$, hablar de "epidemiología clínica" parece un oxímoron epistemológico que junta dos "paradigmas"

4. Para ser precisos, los procesos de inferencia y validación en ciencia no son simples ni utilizan un modo exclusivo de inferencia; su complejidad combina en dosis variadas los tres modos de inferencia identificados por la filosofía y la lógica: la deducción, la inducción y la abducción. El predominio o peso mayor de una -la "dominancia" de que habla Roman Jakobson cuando se refiere a las funciones del lenguaje- define la coloración del método usado. Más aún, en el juicio que hacen los científicos al adoptar sus conclusiones, se combinan intereses epistémicos (por el conocer) con otros intereses; véase la nota 15 para detalles adicionales; véase también N ewton-Smith (2000) para una mirada panorámica del problema de la explicación/ inferencia, y Brown (2000) para la cuestión del juicio científico. 
muy dispares. Por una parte, tal epidemiología acude al modo de trabajo epidemiológico, alineado con las series cuantitativas de observaciones que son sometidas a modelaje estadístico, y más específicamente de probabilidades, siguiendo el "paradigma" de trabajo científico que Ginzburg (1994 [1986]), en un famoso artículo denomi nó "galileano", en honor a su ilustre pionero. En su inferencia domina la inducción, mediante la interpretación probabilística de que las diferencias halladas no sean productos del azar o de factores espurios.

Por otra parte, en el oxímoron clínico converge también el secular "paradigma" "cigenético, adivinatorio, indicial o sintomático" (Ginzburg, 1986: 157) centrado en la situación singular, del cual participa la clínica médica desde Hi pócrates -o antes-. Este modo de diagnosticar tiene que resolver, en un juicio que apela a todos los recursos cognoscitivos y a su capacidad de conjetura ilustrada, la condición singular e irrepetible de un individuo que se siente enfermo. No es el momento de ahondar en la caracterización de este modo sui generis de hacer "ciencia médica", que fue consolidado en el siglo diecinueve en Francia (Foucault, 1966) y cuya sistematización epistemológica general comienza a realizarse hoy bajo el nombre genérico de abducción (Eco y Shebeok, 1989) y método indicial (Ginzburg, 1986). Este procedimiento, como modo alterno de inferencia, al lado de deducción e inducción, inspira el razonamiento clínico tradicional y otros que le son análogos, como el dela jurisprudencia basada en la analogía (Brewer, 1996), y el de los detectives. Como bien lo anuncia Ginzburg y lo elaboran los artículos editados por Eco y Shebeok, Ios ejemplos más populares de la abducción son los del estilo de trabajo de Sherlock Holmes, el héroe de Conan Doyle, de Mr. Dupin del cuento de Poe, y de Zadig, el campesino del cuento traído por Voltaire, todos ellos famosos "detectives". Las bases epistemol ógicas fueron propuestas, según los autores citados, por el pragmatista estadounidense Charles Sanders Pei rce (sobre Peirce y Li pton, véase Misak, 2000, para una mi rada actual a la abducción dentro del proceso general de inferencia, visto desde la filosofía de la ciencia).

La MBE, la seria y desde luego la for dummies, parece haber abdicado de la tradición clínica ancestral -que era indicial, conjetural, reflexiva y abductiva- para al inearse claramente con la tradición "galileana", y dentro de ella con su derivación epidemiológica observacional y seriada (cuantitativista), que a la vez 
es -paradójicamente- individualista. Dentro de este modo de orientar la acción clínica se cae, fácilmente, en las recetas y algoritmos de lógica binaria que en el extremo resultan ser mecánicos, for dummies. Por lo menos eso es lo que se deduce de las orientaciones que ofrecen incluso los más prestigiosos autores -comenzando por el Grupo de MacMaster en Canadá que inició la oleada- en sus tutorials y sus cursos online. Quien lo dude puede consultar los muchos cursos que se dictan por internet, incluso por el exclusivo Oxford Centre of EBM (Oxford Center, 2004).

\section{El Álgebra y EL Fuego:}

LOS QUE JUEGAN CON EL RIESGO DE LOS OTROS

5 L PELIGRO, EL RETO QUE SE IMPONE A LA VIDA Y A SU CALIDAD, EL intraducible hazard de los anglosajones, "es muchas cosas", para repetir la frase de Borges en Hawthorne: no es sólo la amenaza de un daño a la salud del cuerpo o de la vida, por un factor singular externo infeccioso o por desarreglos estructurales o funcionales del organismo. Este fuego-símbolo no es agotado siquiera por el conjunto de los desarreglos psíquicos que estudian los epidemiólogos cercanos a las ciencias sociales como Merwyin Susser (1973, 1985). Hay mucho más, es toda la vida, porque la vulnerabilidad ante el hazard es una condición inherente a la vida humana (Kottow, 2003); cubre todos Ios valores, incompatibles entre sí, de que está tejida la vida, la de los indi viduos y la de los colectivos en que ellos necesariamente están inscritos.

Si el hazard "es demasiadas cosas" también lo es el riesgo y la noción más compleja de vulnerabilidad que lo supone ${ }^{5}$.

Abordamos el álgebra en caliente mostrando que, en virtud del juego de intereses estratégicos, es común que algunas personas o instituciones jueguen -de manera inconsciente muchas veces, y por efecto colateral- con el riesgo para la salud y la vida de los otros. No
5 Es mucho lo que hoy se ha avanzado en la reflexión crítica sobre la vulnerabilidad y su contraparte socio-política, el empowerment (Sevilla et al., 1994). A este avance contribuyó la crisis producida por el $\mathrm{VIH}$, que puso de presente la vulnerabilidad diferencial, llamada por Kottow susceptibilidad, de ciertas categorías sociales, frente a la infección y al manejo de la infección una vez causada (Delor y Hubert, 2000; Bucalla y Palma, 2002). Hoy la vulnerabilidad y su antónimo son objeto de discusiones de punta, tanto en referencia al entorno biofísico (C utter, 2003), al cuerpo de mujeres y hombres (Miller, 2002), como a la salud pública (Kalipeni, 2002). 
nos referimos a los burdos engaños de quienes, por ejemplo, venden licor adulterado. Enfocamos procedimientos más sofisticados, al gunos en que se invol ucran concientemente las víctimas, otros en que se juega a varias bandas, de las cuales unas son claramente estratégicas para proyectos individuales o colectivos que nada tienen que ver con la salud o la vida.

Hemos seleccionado como ilustración ejemplar un caso histórico y le hemos aplicado la reflexión antropológica de una década de trabajo sobre "comunidades maláricas vistas como ecosistemas humanos" (Sevilla, 1989). El ejemplo se trae no con ánimo acusatorio ni de señalamiento individual -que no nos interesa-, sino como recurso analítico que enfoca una práctica institucional que permite enriquecer, con referentes históricoconcretos, la noción socio-antropológica de trama de riesgos distinguiéndola de la noción escueta y estadística del riesgo epidemiológico.

Como "reina de las enfermedades", la mal aria ha impuesto cargas descomunales a la capacidad de sufrimiento de la humanidad durante milenios, y como objeto de la ciencia y acción institucional concertada ha permi tido descubrir la maraña de intereses estratégicos que se ha tejido por algo más de un sigl o detrás del buen propósito de al iviar el mal (Harrison, 1978; Packard, 1984). La malaria permite, a la vez, traer ejempl os muy claros de que una cosa es la eficacia de un tratamiento -o vacuna, cuando la haya- verificado en el Iaboratorio, bajo condiciones controladas, y otra la efectividad de ese tratamiento en la comunidad abierta (Homedes y Ugal de, 2001), en donde -"por desgracia", como se le sol tó a al gún epidemiólogo despistado"se involucran los humanos con sus irracional idades". ¡En ello Ia malaria es, también, "reina de las enfermedades"!

En efecto, su causalidad natural centrada en el ciclo plasmodio-mosquito-ser humano fue establecida gradualmente a partir de 1880 cuando Laveran demostró la responsabilidad de Ios plasmodios; luego, en 1897, Ross demostró la participación del mosquito Anopheles sp. en la reproducción y circulación de I os parásitos. Desde entonces comenzó la batalla sistemática y científica de la humanidad contra ella, dentro del contexto de la colonización de las zonas tropicales por parte de los imperios europeos. Con el tiempo, otros intereses -de orden político, económico, de prestigio- aparecieron para enredar aún más la maraña. 
Factores de riesgo, en el sentido epidemi ológico clásico, serían todos aquellos atributos dela situación humana que facilitan la picadura del mosquito, la patogenicidad del parásito y la susceptibilidad del "hospedero" humano. Factores preventivos los que obstaculizan o impiden los procesos infecciosos. Hasta aquí no habría mayor problema con la epidemiología de la malaria, aunque aun vista así, en este nivel "natural" del análisis, esa epidemiología es extraordinariamente compleja6.

Sin embargo, para un antropólogo o sociólogo estudioso dela cuestión, la causal idad de la malaria no es natural: es histórica y social, es decir, subjetiva-humana, porque los humanos están involucrados. Más aún, difícilmente ellos plantearían la "causalidad" en la forma lineal-temporal en que

6. Para un resumen actualizado de esta complejidad y de la gravedad del problema de la malaria después de más de un siglo de lucha, puede consultarse el Insight de la revista N ature (N ature. 2002. 415(6872): 669.718. la epidemiología trabaja la causalidad -natural-, porque la "causal idad" de los fenómenos humanos tiene el inconveniente de que, a veces, el efecto -como intención o meta: la "causa final aristotélica"- está antes que la causa en la flecha del tiempo cronológi co (Marini y Singer, 1988). Por ello, en ciencias sociales poco se habla hoy de análisis causal como se hace en las ciencias naturales (Bhrolchain, 2001), aunquetambién en éstas comienza a flaquear esta estrategia analítica (Giere, 1988: 104-105 Humphreys, 2000).

A ningún epidemiólogo común y corriente, incluso si sigue a Susser (1973) en los análisis ecológicos de la causalidad en cuestiones de sal ud, se le ocurriría pensar que una trama de intereses institucionales y personales pueda consi derarse como "factor de riesgo de malaria", o como eslabón condicionante -"causal"- de la enfermedad. Para la visión simplista, de causalidad natural, así sea "ecológica" -al estilo de Susser- esa trama no facilita la picadura, como lo hace la proliferación de charcas de agua cerca de las viviendas en zonas tropicales, o lo hace la ausencia de toldillos. Sin embargo, para un sociól ogo o antropólogo que conozca la historia de la enfermedad como proceso social (Jeffrey, 1976; Palacios-Fraire, 1975) esa trama de acción puede interferir con el propósito general de mantener la morbi lidad y mortal idad por malaria en un nivel ya conseguido o conseguible: es decir, aumenta el riesgo demal aria para determi nadas poblaciones. Esas decisiones subjetivas, esos juegos de intereses estratégicos, que pueden tener metas implícitas o inconscientes distintas de las de 
Álgebras y tramas en el cálculo de riesgos

controlar la malaria-aunque sepresuma la buena fey se hablede efectos colateral es ${ }^{7}$-, pueden darse en todos los nivel es y campos del fenómeno histórico que denominamos "ecosistemas humanos de malaria" (Sevilla, 1989).

Para no ir lejos en la larga historia -que comienza a ser reescrita críticamente en el ámbito mundial por autores como Litsios (1996; 2001)- resulta interesante proponer la hipótesis de trabajo - analítica, no acusatoria, que demandaría investigación detenida- de que, en las últimas décadas, ha habido tramas de acción de altos funcionarios gu-

7. John Searle (1983) ha analizado en detalle la cuestión de la intencionalidad y la de sus efectos colaterales. El daño de que hablamos puede ser un efecto colateral que, sin embargo, no deja de ser daño medible en tasas objetivas: los plasmodios no saben de intenciones humanas, simplemente, se reproducen y al hacerlo causan los síntomas de la enfermedad en los humanos. bernamentales y deentes internacionales, combinada con la de científicos amigos de la auto-exaltación y de periodistas que hacen el juego de resonancia al rededor dela muchas veces anunciada vacuna contra la mal aria. Por sus resultados en las tasas efectivas de malaria, parece que la trama ha interferido en el propósito de mantenerlas a raya en las poblaciones endémicas o en el más optimista de mejorar su control con los medios tradicionales.

El caso es el siguiente: en el convencimiento -sin duda de buena fe- de la eficacia, efectividad y cercanía de la vacuna antimalárica, se ha tejido una trama que combina la generosidad notable de parte de las instituciones y personas privadas con las ávidas demandas de recursos y reconocimi ento por parte de investigadores que -sin duda también de buena fe- se han dedicado a producir "Ia vacuna" y a anunciar, anticipada e infundadamente, la aplicación casi inmediata de las mismas.

En el caso que nos ocupa, el proyecto SPf66 de Manuel Elkin Patarroyo, no habría motivo para sospechar tramas humanas de riesgo de malaria, si hubiera habido abundancia de dinero, y sobre todo, si no se hubieran hecho anuncios irresponsables en Ia prensa habl ada y escrita, a partir de 1987 cuando fueron publicados I os primeros resultados. Ejemplos de los muchísimos anuncios son: "La vacuna contra la mal aria es real idad" (El Tiempo, 17 de marzo de 1991), "El año entrante se espera vacunar a un millón depersonas" (El Tiempo, 9de noviembre de 1992). Los periodistas hicieron anuncios espectaculares como los citados, que respondían a la sed de fama personal del investigador principal y al 


\begin{tabular}{r|r}
$\begin{array}{r}\text { Revista Colombiana } \\
\text { de Antropología }\end{array}$ & 31 \\
volumen 40, enero-diciembre 2004 &
\end{tabular}

afán de dar noticias sensacionales, que desencadenaron el nacionalismo tropical de agentes gubernamentales, quienes, obnubilados por los premios y premios obtenidos por el investigador, merced a esa misma resonancia, Ilegaron hasta anunciar que "la OMS y el gobierno acordaron las políticas y el cronograma para recibir la patente y producir la vacuna, queal canzará en 1995un total de 80 millones de dosis mensuales, para combatir la enfermedad en todo el mundo" (El Tiempo, 9 de junio de 1993).

Los hechos fríos nos dicen que hoy, después de diecisiete años de pirotecnia periodística al rededor de la SPf66, Ios resultados prácticos y aplicables en las zonas endémicas están, como los de otros muchos candidatos a la vacuna, aún muy lejos de justificar tal es anuncios. Repetimos que se trata de un caso ejemplar de tramas institucionales de acción, no de la culpación a determinados individuos, así ellos hayan tomado parte central en las mismas y se consideren en el ojo del huracán del reconocimiento o de la incomprensión? ${ }^{8}$.

Al respecto, como se trata de asuntos muy serios de orden científico y de salud pública, es preciso despejar la fronda propagandística y parroquial para atenerse a las evaluaciones serias e independientes al respecto: consúltese, por ejemplo, la muy reconocida Cochrane Review (Graves y Gelbhand, 2004), acogida también por un Insight de la prestigiosa revista Nature:

En un recientemeta-anál isis de nueve pruebas queinvol ucraron 9.800 vol untarios, Graves y Gel bhand concluyeron que no había evidencia
8. Es preciso insistir en que no es de nuestro interés centrarnos en determinadas personas, por más importantes que ellas se crean, ni menos acusarlas por su eventual responsabilidad moral. Todo lo contrario, presumimos su buena fe. Nuestro análisis es histórico y analítico, centrado en los resultados objetivos de un proceso que lleva más de un siglo en donde juegan ante todo las instituciones (Douglas, 1986a; 1992) y en donde los efectos en términos de morbilidad y mortalidad están claros, así sean colaterales, al margen de las intenciones de los actores implicados. Tomamos este caso institucional como ejemplo de un hilo que se ha hecho evidente en la trama compleja que hoy tiene la malaria de Colombia. Podríamos haber tomado otro ejemplo, de pronto no tan espectacular, porque estos esquemas institucionales se repibastante en el campo público y privado y allí los investigadores aparecen a veces como títeres en un montaje de publicidad y autoimagen que está en manos de periodistas irresponsables. De hecho, hay otro caso colombiano, más reciente, centrado en la malaria anti-vivax -la de Patarroyo es antifacilparum- que, a pesar de los anuncios de los científicos involucrados de "no seguir el camino de Patarroyo", parece estar tomando los mismos perfiles. El Tiempo, del 13 de junio de 1993 anunció que "en unos meses Colombia podrá contar con una nueva vacuna contra la malaria [...] se espera aplicarla a voluntarios al comenzar el próximo año". De hecho, en este caso las pruebas con voluntarios -que suponen luego un largo camino para "tener en serio una vacuna" (véase la nota 10 )- se iniciaron casi una década después. 
de eficacia para SPf66 en África pero que ella causaba una modesta reducción de los ataques de mal aria en Sur América (Richie y Saul 2002: 697).

Y sobre la esperanza actual de tener una vacuna "a la mano" para poblaciones endémicas los autores de la nota de Nature agregan:

Aun dentro del más optimista esquema de ilimitados recursos, se
tomarían muchos años a partir de ahora, requiriéndose pruebas
iterativas de combinaciones mejoradas y formulaciones para que se
logre suficiente eficacia. Entretanto hay mucho que hacer para
asegurar que cuando las vacunas estén disponibles, Ias
infraestructuras desalud estén en capacidad deadministrar programas
integrados que usen las vacunas efectivamente. Esto puede ser un
reto tan grande como la vacuna misma (Richiey Saul, 2002: 700).

Aquí asoma su cabeza la cuestión de la efectividad -versus la eficacia- arriba mencionada: una cosa es tener la vacuna en el laboratorio -si es que se puede tener una eficaz contra un parásito tan elusivo y camal eónico- y otra lograr su aplicación efectiva en las comunidades, particularmente cuando se trata de vacunas cuyos efectos son temporales ${ }^{9}$.

Este caso del proyecto Spf66 puede parecer un vulgar juego de competición entre investigadores, una puja por obtener prestigio

9. Estas apreciaciones cambian poco después del éxito de la vacuna experimental RTS,S/A02A, producida por un equipo dirigido por el español Pedro Alonso (Alonso et al., 2004); de modo interesante, este investigador en una entrevista publicada en El Tiempo habla claramente del fracaso de la vacuna de Patarroyo y de las causas del mismo (Vargas, 2004) (véase la nota 10 ). y recursos, inocuo en materia de riesgos demalaria-y deprevención de la misma-. Pero es razonable pensar también en la hipótesis de que la trama de intereses y de acción en la que muchos han jugado pudo, así mismo, haber tenido resultados graves y mortales en el caso de Colombia. Cualquiera que haya revisado la prensa nacional y regional en las fechas cercanas a las pruebas tiene que reconocer que hubo publicidad exagerada sobre la cercanía de una vacuna efectiva para quienes más la necesitaban, los de las zonas endémicas: con esta propaganda, en la forma en que se hizo, y avalada por el establishment científico y para-científico nacional y uno que otro ente internacional, el esfuerzo de décadas de educación popular, incluso el esfuerzo institucional local para el control de la enfermedad por medio delos 
modestos pero efectivos medios tradicionales pudo haberse venido al piso10. "Como ya tenemos la vacuna, para qué tol dillos y para quéjoderse tanto; más cuando quien la produjo es un colombiano candidato al Nobel, model o de generosidad porquela regaló a la OMS para beneficio de la humanidad. A ponernos la vacuna, y ya, no más mal aria".

Lo triste es que la trama continúa y se agrava. Con argumentos que cada día suenan más irrealistas, después de asignaciones nacionales cercanas a los cincuenta mil millones de pesos obtenidos a la sombra del proyecto de vacunas, todo apunta a una demanda contra el Ministerio de la Protección Social para que asigne más recursos (Quevedo, 2004). De ganarsela demanda, los recursos se sustraerían de lo destinado a las necesidades urgentes de mantener a raya la enfermedad con los medios tradicionales. Habría que investigar, frente a los impresionantes datos demorbilidad y mortal idad por malaria en Colombia, si esta ridícula pirotecnia y este desvío de recursos por parte de un Ministerio que acusa déficit crónicos para lo esencial -incluido el control tradicional de
10.En 2004, la revista Lancet, la misma que publicó algunos de los resultados de la SPf66, dice sobriamente sobre una nueva vacuna: "Los intentos de desarrollar una vacuna antiesporozoítos datan de los años 1970, y la historia reciente de la vacunología nos dice que el desarrollo de una vacuna es un proceso desesperadamente largo. Se necesitan con frecuenca décadas desde las pruebas preclínicas de los candidatos a vacunas hasta la licencia y la disponiblidad pública. La cooperación actual público-privada sin precedentes para el desarrollo de vacunas de malaria, con agencias nacionales e internacionales que comparten metas, debe acelerar este proceso lo más que se pueda e impulsar innovaciones. El productor de la RTS,S/ASO 2A, G laxoSmithKlineBio, podría lograr la licencia de esta vacuna para 2010. En todo caso, la vía hacia una vacuna de malaria segura y eficiente que esté disponible y sea usable en gran escala, o aun incorporada en el programa ampliado de inmunización, será larga y caótica. Por tanto, durante muchas décadas por delante, la expansión de estrategias preventivas y terapéuticas, incluyendo aquellas nuevas que tienen un evidente valor agregado - por ejemplo, toldillos impregnados de insecticidas y tratamiento con regímenes que contengan artemisina- deben mantenerse como de alta prioridad para parar la hecatombe malárica. Paralelamente, se necesitan nuevos desarrollos en drogas que enfrenten la expasión mundial de la resistencia del Plasmodium spp. Más que nunca, los infantes, los niños menores y las mujeres embarazadas, que son fuertemente afectados por las consecuencias directas e indirectas de la malaria en las áreas endémicas, necesitan en todo el mundo el compromiso científico, político y financiero. Este compromiso es una cuestión de ética, de derechos humanos y de exposición para la mitad de los habitantes del planeta (Van de Perre y Dedet, 2004).

la enfermedad-, no se han combinado para mantener las tasas en franco ascenso in interrumpido -lo cual muestran las series detiempo producidas por los epidemiólogos- (Osorio, 200327 ).

Saliendo de Colombia y pensando en el mundo, el diagnóstico y pronóstico es igual mente preocupante: cada año se enferma clínicamente por malaria una décima parte de la humanidad y muere un millón de personas. Peor aún, hay signos de agravamiento del problema (Weiss, 2002) aunque también 
Álgebras y tramas en el cálculo de riesgos

hay en perspectiva nuevos recursos, que tendrán beneficiarios nuevos y voraces.

Alguien puede revertir el argumento y decir que, precisamente, por ser tan grave el pronóstico hay que dar prioridad a las "grandes soluciones" como la vacuna, más cuando ell as están en manos de "titánicos quijotes", "del os espíritus más nobles y grandes que en el mundo han sido", como se le respondió al periodista que indagó sobre el asunto (Quevedo, 2004). Quienes así piensan desconocen tal vez, u olvidan estratégi camente, las decepciones causadas por las prometidas "balas mágicas" en el pasado de la campaña antimalárica. Sobre ellas, tan temprano como en 1927, la Comisión de Malaria de la Liga de las Naciones escribió, mucho antes del fracaso de la bala mágica de la erradicación con el DDT: “La historia de las campañas especial es antimaláricas es ante todo un record de expectativas exageradas seguidas, tarde o temprano, de desilusión y abandono del trabajo" (en Jeffrey, 1976: 366). Se dirá que es cuestión de opinión y que con las vacunas eso no pasará. Sin embargo, de por medio están las al tas tasas de morbilidad y de mortalidad, estas sí efectivas, que pudieron verse afectadas en el pasado por las expectativas, exageradas y fal sas, que se le vendieron a la gente, a la de arriba y a la de abajo. La historia lo dirá -la que lleva más de un siglo-.

Para redondear el caso ejemplar: por la naturaleza misma del asunto, histórica y compleja, es bastante difícil hacer atribuciones cuantitativas precisas a este tipo de "factores de riesgo" humanos, pues se trata de tramas institucionales e individuales de intereses varios, que se interponen entre las medi das abstractas -tradicionales o no- para contener el flagelo y las poblaciones víctimas del mismo. Pero el hecho de que sea imposible en este tipo de situaciones contar series y luego calcular el peso estadístico de estos "factores de riesgo" demalaria, no implica que no se trate de un conjunto de hilos, de pronto muy importante, en el complicado tejido de ese riesgo. El ejemplo invita a concluir que es necesario dejar de pensar sólo en factores de riesgo contables y medibles, y pasar a hablar también de "tramas de riesgo" y "tramas de factores", es decir, a pensar relacional e históricamente.

Estas ál gebras pragmáticas orientadas a eficacias concretas centradas en intereses mundanos o extra mundanos -piénsese en las creencias religiosas que impiden el acceso a transfusiones, por ejemplo- son muchas y de diversa capacidad de ilusión frente 
a la disposi ción del cliente-o dela víctima- o de quienes tienen la obligación de velar por su salud y asignan los recursos. A cada riesgo para la sal ud y la vida, el investigador, que está atento a este mecanismo transformador de la imagen del riesgo y de su complejidad, puede hallarle una completa red de intermediarios, que se ubican -con sus ál gebras pragmáticas- entre el cliente/víctima y "la grieta”. Hacen parte de la "lámina que mantiene nuestro mundo ilusorio" -recuérdese la cita de Borges-; ella se interpone entre nosotros y el abismo. En sus gruesos pliegues se define el riesgo de las potenciales víctimas.

\section{El Álgebra y EL Fuego: \\ QUIÉNES CORREN EL RIESGO}

V

LLEGAMOS, POR FIN, AL ÁLGEBRA DE QUIENES SUFREN EVENTUALMENTE el daño. En el pliegue o estrato inferior de la placa interpuesta entre nosotros y el abismo -el último pliegue hacia el abismo, o ya dentro del abismo- está el álgebra de quien corre el riesgo, del individuo que, como cliente o víctima, sufre las eventuales consecuencias.

Tomemos como ejemplo un evento cotidiano que quita el sueño no sólo a padres de familia sino a cualquier autoridad responsable de nuestro país. Una joven cal eña de diecisi eteaños se va "de rumba" con su novio y un grupo de amigos y termina regresando a casa hacia las tres de la madrugada en el auto de su pareja en avanzado estado de embriaguez. Ante una mente simplista la "irracional idad" de la chica podría ser considerada como un acto de rebeldía juvenil, pero es bueno escuchar la versión del protagonista varón, cuando pos festum responde en una entrevista de evaluación retrospectiva y hace comentarios aplicables a este tipo de conducta:

¿Cuál es el rol dela mujer al lado desu pareja ebria? Es como cuidarlo un poco, él no leva a ceder el timón porqueél cree como la canción que a él el alcohol no le altera los sentidos, simplemente él siente queva a estar bien, además porque él es el hombre, entonces en esa cultura machista el hombre es el que maneja, el que tiene la plata. El asunto aquí es quel os hombres nos creemos los dueños dela película, somos los que pagamos la cuenta, los que invitamos las viejas, los que decidimos si la rumba continúa o se queda allí, y las mujeres 
Álgebras y tramas en el cálculo de riesgos

termi nan siendo un poco como a ver lo acompaño hasta dónde, porque usted la va a cagar más si no lo acompaño, venga estoy más bien cerca de usted porque si no usted se emborracha y la caga y yo estoy allí para ayudarlo y soportarlo... Yo pienso que es más su actitud como maternal la que la hace quedarse allí, como con la intención de cuidarlo. Ella sabe que a ella no les gustaría estar allí, a ella le parece incómodo, lo mira y a veces yo estoy con mis amigos borrachos y ellos van con una vieja y ellas mi ran cómo este man la cagó porque va borracho, decile que te délas Ilaves y yo le digo ni pa quéintentar, ese man no me va a dar las llaves, más bien subámonos aquí y esperemos que este man nos Ileve a la casa, (...) entonces él se sube y la vieja como que dice yo lo voy a acompañar porque quétal quese emborrache más y quétal quela cague, o quétal queledéalgo, como queella termina con el beneficio secundario de ganarse la imagen de una buena mujer, una buena compañera, dela vieja queacompañó al man cuando está borracho, así ella diga qué mamera este hijueputa borracho, en todo caso ella va a tener la sensación de que, por un lado, eso fue lo que le enseñaron, usted tiene que estar allí para acompañarlo a él, y por otro lado ella se gana el beneficio de que al otro día él le diga uy amor, vos cómo teaguantaste, qué pena contigo, vos sos una berraca, cómo no te has ido. Otra cosa es que yo a veces siento quees una manera de controlarlo allí, porquees queél borracho podría hacer otra cagada como ir a buscar la ex novia, entonces yo más bien me quedo porque que tal que

11. Fuente: entrevista de trabajo de campo en Cali, 2004. Tesis doctoral, T. Sevilla. este hijueputa se vaya para dondela ex novia, o se vaya donde otras amigas, si yo no estoy con él quétal quesevaya con el amigo solo y no ll egan a la casa sino dondeotras dos viejas distintas, entonces yo mejor mequedo... ${ }^{11}$.

El caso deesta chica, o el del chico que conduce embriagado, es análogo al de la trabajadora sexual que distingue entre los clientes-clientes y los clientes-amantes para el uso del condón, o de la mamá que no compra el toldillo para su bebé porque El País de Cali publicó en primera plana que ya tenemos la vacuna del doctor Patarroyo.

En su relación con el mundo, más acá de los automatismos corporales, biológicamente condicionados, como el parpadeo, la mente individual construyeal actuar sus model os implícitos, su álgebra del hacer, para usar el término de Judea Pearl (2004), en contraposición con el álgebra del ver. Estamos, en el lenguaje de Pierre Bourdieu (1980b) en su conocido texto El sentido práctico, frente al sentido del juego, contrapuesto a las reglas del juego, que corresponden a las ál gebras abstractas -por cuanto éstas hacen abstracción de las limitaciones del espacio/tiempo-. 
Esta álgebra primera -o última-, la del actor que toma decisiones -o deja de tomarlas, lo que es también una decisión-, no es sencilla en su estructura. Parece estar estratificada en una jerarquía que va desde lo implícito e inconsciente hasta lo explícito, consciente y verbalizado, pasando por una franja en donde sólo opera "el lenguaje del pensamiento", el "mentalés" previo al lenguaje intersubjetivo (Pinker, 1997).

Los psicólogos de la cognición han hecho propuestas para demarcar tentativamente estos estratos de las ál gebras mentales, pre verbales y verbales. Hablan de un nivel implícito elemental (I) en dondeel ál gebra-si es queasí puede denominarseestá estructurada como un mecanismo estrictamente procedimental; se asciende de allí a un nivel explícito primero (E1) en donde ya hay representaciones explícitas de los componentes procedimentales que pueden relacionarse entre sí, es decir, ya se da el juego de símbolos que caracteriza al álgebra propiamente dicha; viene luego un segundo nivel explícito (E2) en que las representaciones emergen al horizonte de la conciencia; y, finalmente, se da un tercer nivel explícito (E3), en el cual las representaciones conscientes son verbalizadas. De allí en adelante, las representaciones entran en el juego abierto de la comunicación intersubjetiva (Karmil off-Smith, 1992).

Al bosquejar estos niveles que se sobreponen sin anularse en el individuo queactúa y reflexiona para sí - ¡cuando reflexiona!- frente al riesgo, no nos hemos salido, todavía, del campo pragmático y situacional propio del discurso de legos. Merced al recurso del lenguaje y la comunicación ha sido posible que estas primeras representaciones tomen francamente el camino intersubjetivo, es decir, se expresen en la conversación cotidiana; luego, pueden entrar en el camino franco de la abstracción, cuando los expertos procedan a construir sus model os científicos, Ios cuales, poco a poco, dejan de estar "en caliente" para convertirse en fórmulas "en frío".

Con este último proceso de abstracción y refinamiento científico ocurre una paradoja: senos ha hecho creer, debido al enorme prestigio que tiene el discurso científico, comparado con el conocimiento de los legos, que a medida que se aparta de la situación concreta -pues la ciencia es esencialmente generalizadora- esa ciencia nos pone en contacto con la realidad, que está más al lá de las si ngularidades fenoménicas. En los térmi nos de Borges, se nos ha hecho creer que es el ál gebra -juego de 
pal abras vacías, máquina de la información- la que vale por el fuego, por la grieta, "el horror esencial de la vida humana". Sin embargo, parece no ser así. Un afamado filósofo de la ciencia, Paul Feyerabend, escribió así en su libro póstumo:

La búsqueda de la real idad que acompañó la civilización occidental cumplió un papel importanteen el proceso de simplificar el mundo. Esto se presenta usual mente como al go positivo, o como una empresa quelleva al descubrimi ento de nuevos objetos, rasgos, rel aciones. Se dice que abre nuestros horizontes y revela los principios detrás de los fenómenos más comunes. Pero esta búsqueda tiene también un fuerte componente negativo. No acepta los fenómenos como ellos son, los cambia, sea en el pensami ento (abstracción) sea interfiriendo activamente con ellos (experimento). Ambos tipos de cambio involucran simplificaciones. Las abstracciones remueven las particularidades que distinguen un objeto de otro, junto con otras propiedades como el color y el olor. Los experimentos remueven adicional mente, o intentan remover, los lazos que unen cada proceso con su entorno -crean un entorno artificial y de algún modo empobrecido y exploran sus peculiaridades-. En ambos casos, las cosas son quitadas de en medio o "bloqueadas" frente a la totalidad que nos envuelve. Lo más interesante es quel o que queda es II amado "real", Io cual significa que eso es más importante que la misma totalidad. Más aún, esta totali idad se describeahora como consistente en dos partes: un mundo real oculto y parcialmente distorsionado y un velo a su al rededor que lo oculta y perturba. La dicotomía ocurre no sólo en la filosofía occidental y en la ciencia, también ocurre en contextos religiosos y al lí puede estar combinada con la dicotomía entre el Bien y el Mal [...]. [Feyerabend, 1999. 5].

\section{LAS ÁLGEBRAS DEL RIESGO}

EN LA SOCIOLOGÍA Y LA ANTROPOLOGÍA

n SOCIOlogía SE ha esCRITO mUCHO PARA COMENTAR LAS IDEAS DE Ulrich Beck, Anthony Giddens y Niklas Luhmann sobre "la sociedad del riesgo", aun cuando años antes la antropóloga Mary Douglas (1966, 1982, 1986b, 1992) había hecho incursiones decisivas en el difícil campo de la investigación y teorización científica del riesgo. No vamos a hacer una reseña de esta literatura, que puede consultarse en obras de autores muy especializados (Lupton, 1999; Lupton y Tulloch, 2002a y 2002b; Williams et al., 2003), aparte, desde luego, de la consulta directa de los mencionados, cuyas obras son harto conocidas. Basta 


\section{Revista Colombiana \\ de Antropología

aquí una idea global de "la sociedad del riesgo" para seguir con nuestro argumento, centrado en las ál gebras del riesgo, en frío y en caliente, con referencia al ámbito de la salud pública. Según el libro Modernización reflexiva: política, tradición y estética en el orden social moderno (Beck, Giddens y Lash, 2001: 18), Ia sociedad del riesgo designa "una fase de desarrollo de la sociedad moderna en la que los riesgos sociales, políticos, económicos y de otro tenor tienden cada vez más a escapar a las instituciones de control y protección dela sociedad industrial" [énfasis nuestro]. En la sociedad contemporánea, en la que se ha radicalizado la modernidad, se vive en una situación de "incertidumbre fabricada" (p. 220).

En términos de nuestro argumento, los riesgos tienden a escapar a la capacidad de intervención racional que reposa en las ál gebras abstractas que hemos bosquejado, tomando como ejemplo la epidemi ología. Lo hemos dicho antes: hay una intransitividad entre los análisis/recomendaciones de los estudiosos y los efectos buscados, que obedecen a lógicas demasiado complejas como para que puedan ser capturadas por los modelos predictivos de base cuantitativa.

La razón profunda de esta intransitividad fue expuesta hace tiempo, y en varios libros, por Mary Douglas: en asuntos humanos no hay riesgos objetivos puros, porque todos los riesgos -entre ellos los de la salud y la vida- son construcciones colectivas y su interpretación, que hace parte del riesgo, es, también, inevitablemente cultural y subjetiva: no pueden no pasar por el lente cognitivo, e interesado, de los actores que -en nuestra metáfora borgeana- están en la grieta, inmersos en el fuego. Además, cualquier aproximación al riesgo que parta exclusivamente del individualismo metodológico está destinada, según la autora, a ser improductiva (1992: 321).

Dougl as (1992) nos recuerda, además y de manera clave para nuestro propósito analítico, que la "predisposición" o connotación exclusivamente negativa en el uso del concepto de riesgo, con referencia a sus efectos, es una fabricación de los expertos en los tiempos modernos. Su acepción original, rastreada hasta los lejanos tiempos de los comerciantes europeos de los siglos quince y dieciséis, consi deraba al risicho como una apuesta, un salto a lo profundo y desconocido de los mares y las aventuras de tierras no nombradas, a merced del clima y otros avatares humanos y no humanos, que podría implicar no sól o la pérdida total de las inversiones económicas que los comerciantes, 
marineros y demás interesados hubiesen hecho, sino la muerte misma o el deterioro permanente de la reputación como mercaderes. Sin embargo -y tenemos aquí un matiz de sentido que se ha diluido en el tiempo- risicho podía significar también una jugada estratégica, un logro importante, en términos económicos y comercial es, que cambiaría positivamente para si emprela vida de los avezados aventureros.

Volvamos a este siglo y a los casos empíricos bosquejados arriba, para armar al guna plataforma de interpretación socioantropológica que complemente los rigurosos avances de la epidemiología. Comencemos por mirar lo que denominaríamos las tramas objetivas -estructurales, institucionales- queenmarcan los riesgos y los determinan, como se vio en el caso de los deportes extremos o de la malaria. Como vimos, hay una complicada trama de intereses de los comercializadores del riesgo o de los que tienen el daño-la malaria- como pretexto para sus propios fines, que son parte de la definición histórico-concreta de los riesgos objetivos. Con frecuencia, esas tramas de intereses se institucionalizan, es decir, adquieren un cuerpo objetivo instituido, observable en patrones de organización social y de conducta. Douglas (1987; 1992: 321) sostiene que la única manera de trabajar bien la noción de riesgo es articularla al papel decisivo que desempeñan las instituciones en las decisiones individuales (1986a). Dentro de esta institucionalización, los actores, quetienen intereses en juego, construyen el sentido de los riesgos y, final mente, juegan con él, es decir, participan en la secuencia de eventos en donde emergen las tramas de acción que concretan los riesgos en cuestión.

Hace poco más de un sigl o, Emilio Durkheim ([1895] 1987), considerado padre de la sociología -y de la antropología por medio de Marcel Mauss-, defendió radicalmente el tratamiento de los fenómenos sociales como "cosas" del mundo extenso, es decir, susceptibles deser trabajados con métodos rigurosamenteobservacional es y cuantitativos. Lo que Durkheim excluyó tajantemente en sus Reglas del método sociológico fueron las representaciones subjetivas de los actores involucrados en los fenómenos sociales (véanse detalles en Dantier, 2003). De ser aplicadas tal como las formuló, estas reglas excluirían todo el componente subjetivo que según la sociología y antropología contemporáneas, a partir de Douglas, Giddens, Beck y Luhmann, hacen parte ineludible de la constitución del riesgo. Años después de Durkheim, no muchos, porque 
fue en los veinte del siglo pasado, otro autor, padre también de la sociología, Max Weber ([1922] 1944), centró toda su obra en el sentido mentado, es decir, en la representación subjetiva simbólica y comunicada de las situaciones concretas que se hacen los actores que están en juego en determinada situación, como es la de nuestros casos de riesgo. Con razón, Weber es tenido como el padre de la sociología comprensiva. Años más tarde, en la década de 1970, Clifford Geertz ([1973] 1995), un antropólogo reconocido como el padre dela antropología interpretativa, tomó en serio las ideas de Max Weber cuando afirmó que el ser humano es "un animal inserto en una trama de significación que él mismo ha construido" y propugnó que la antropología fuera "una ciencia interpretativa en busca de significaciones".

Estamos, por tanto, frente a las tramas de acción humana ${ }^{12}$ y en los párrafos que siguen tratamos de advertir en ellas varios estratos analíticamente interesantes:

1 Podemos hablar, en primer lugar, de tramas institucionales o estructurales, queson las plasmaciones objetivas-físicas y normativas- que definen el contexto de una situación de intere$\operatorname{ses}^{13}$ cualquiera, en estecaso, una situación en queun individuo o un conjunto deindividuos corren riesgos. Decimos riesgos, en plural, porquedebesuperarsela idea -abstracta y de laboratorio- de que los riesgos existen como ánimas solas: el riesgo de una infección por VIH o de un embarazo adolescente, mirado como el solo foco de interés, es una abstracción del epidemiólogo o salubrista. Ese riesgo, como el demonio del Evange-

12. Trama tiene en el Diccionario de la Real Academia tres sentidos: 1) urdimbre de hilos que forman un tejido o seda para tramar; 2) artificio, dolo, confabulación, que perjudica a alguien; 3) y el "enredo" (plot) de una obra dramática. Por su carácter relacional, las tramas a que nos referimos no se cuentan, se comprenden.

13 Weber (1944: 23 define la situación de intereses precisamente en oposición a la regularidad en la conducta humana, nacida del uso y la costumbre; en ella la búsqueda de unos fines condiciona el resultado de la acción, que se sale de los patrones usuales.

lio que tentó a Jesús, es legión. Las situaciones humanas, las equivalentes al fuego borgeano, son muchos riesgos a la vez. Su trama, y la jerarquía valorativa de ellos dentro de la trama, depende de la percepción y eval uación subjetiva de quie nes tienen el sentido del juego; y el juego es un proceso en el que -con ritmos variados- se producen cambios en las relaciones múltiples, normalmente interesadas, que constituyen 
esas tramas. Son situaciones de intereses, para usar la expresión weberiana.

2. En esas situaciones pueden advertirse las tramas de sentido que tejen los actores insertos en las tramas institucionales. Esos actores son muchos, porque así lo pide la noción misma de institución. Rarísima vez en situaciones humanas concretas hay un solo actor, y, menos, un solo actor completamente racional. Aun en situaciones aparentementeindividual es, hay varios actores involucrados, si no de manera directa al menos mediante el cumplimiento de tramas institucionalizadas que, por definición, han implicado la participación de muchos. Cada uno de estos actores tiene su propia visión del campo de juego y su posición en la estratificación de las estructuras institucionales.

3 Pero, como bien lo mostró Habermas (1971), no hay sentido -conocimiento- sin un substrato de intereses que jerarquiza los val ores que los seres humanos conceden a las cosas y eventos que conocen. Las significaciones no son neutras en cuanto a val oraciones, sino quetienen una posición jerárquica, quecambia, de acuerdo con las prioridades de la vida. Por tanto, las tramas de sentido son, a la vez, tramas de intereses. Ejemplos de ellas los tenemos en el caso de la malaria que es, al tiempo, preocupación por lasal ud pero también pretexto o instrumento para otros fines. Lo primero para las víctimas, lo segundo para ciertos investigadores demalariainteresados, antetodo, o paral elamente, en su propio prestigio y ascenso social; y lo tercero, por ejemplo, para algunos estrategas militares que ven en la mal aria un peligro grave para sus incursiones ocasionales -no por nada las fuerzas militares deciertos países tienen enormeinterésen las vacunas que, como temporales que son, servirían en primer lugar, y de pronto sólo, para proteger incursiones ocasionales; a los locales de las zonas endémicas que se los coma el tigre.

Y en cuanto a la racionalidad de medios a fines, que según Weber está detrás de las situaciones de intereses, es preciso advertir que los fines no implican necesariamente la aversión del riesgo: a veces ocurre que correr el riesgo es un fin buscado, es decir, adquiere la coloración positiva de fin en sí mismo, no de medio, en la valoración de los actores. Así retornamos a la noción antigua de riesgo que, como señaló Mary Douglas (1992), son equival entes a los retos de la vida. 
Más aún, hay estudios empíricos contemporáneas (ejemplo, Lupton y Tulloch, 2002b) que hacen ver que para al gunas personas, sobre todo jóvenes, la vida sin riesgos sería insulsa.

Cuando se guían por el individualismo metodológico o por el empirismo lógico, la sociología y la epidemiología se horrorizan de esta subversión de la noción de riesgo, y arrojan a las tinieblas exteriores del irracionalismo determinados comportamientos (por ejemplo, Elster, 1989, dentro de la sociología). Otras aproximaciones, más flexibles ante el "fuego" de la "grie ta", dan importancia al juego (play y game) quejuegan los seres humanos cotidianamente. Roger Caillois (1986), por ejemplo, distingue en el juego de los seres humanos por lo menos cuatro vertientes, que a veces se conjugan: el agon o placer dela competencia; el alea o azar; la mimicry o imitación; y el ilinx o vértigo (véase también Duvignaud, 1980). No es el momento de ahondar en esta perspectiva que arroja mucha luz sobre comportamientos que para la vista de las ál gebras abstractas resultan, como dice Borges, completamente escandal osos.

4. Y como resultado de este ejercicio biográfico-histórico se dan, finalmente, las tramas de eventos, la ejecución de los libretos $^{14}$, que no siempre resultan, para cada actor, como se tenían pensados. Todos sabemos, en efecto, que dondehay tramas de intereses hay desigual dades de poder quetuercen los eventos. Por tanto, los actores que corren los riesgos -o los hacen correr-conforman aquel proceso histórico, único, irrepetible, que sellama la trama de la acción humana, en este caso la acción como secuencia de eventos quetienen efectos considerados dañinos para los seres humanos, y en los cuales, con el bisturí analítico, hemos descubierto algunos estratos. No olvidemos que debajo de esta placa simbólica operan las fuerzas ciegas de la natural eza de las que depende buena parte de los daños en que se interesa la salud pública.

14. Hay una propuesta interesante de Simon y G agnon (1986), la teoría de los libretos sexuales, que puede leerse dentro del presente marco analítico de tramas. Esta teoría, como todo lo que hable de libretos, se inscribe dentro de la gran vertiente analítica que en antropología G eert (1994) hace basar en la metáfora del drama, así como la propuesta de Caillois (1986) trabaja la del juego. Lo importante es tener en cuenta que las metáforas, la teatral y la del juego, en el trámite de los riesgos, no son simuladas: van en serio, tienen efectos dañinos, de veras; del mismo modo, no debe olvidarse que las jerarquías de poder y dominación y los intereses estratégicos también van en serio; todo ello se conjuga para que los riesgos de vida o muerte o de daños serios al bienestar general de las personas aumenten, rara vez disminuyen, cuando uno no maneja bien estas metáforas. 
Con estos antecedentes de orden conceptual procedemos a plantear algunas implicaciones técnicas para la cooperación con la epidemiología.

\section{Á lgebras cooperativas \\ Y CONSIDERACIONES TÉCNICAS}

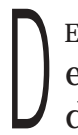

ESDE LA CONCEPCIÓN EPIDEMIOLÓGICA DEL RIESGO SE HAN HECHO esfuerzos ingentes y admirables para acercarse al "fuego" de la vida. El "álgebra epidemiológica" de un importante maestro de epidemiól ogos y ejemplo de humanismo frente a la tragedia del VıH/sida en África, el médico sudafricano Mervin Susser, de Columbia University, es una instancia ejemplar: pudo escribir con el antropólogo William Watson el libro Sociology in medicine (1985) e hizo esfuerzos notables para aplicar el razonamiento epidemiológico a fenómenos tan complicados como la úlcera péptica, y, sobre todo, a dolencias psíquicas como la esquizofrenia. Sin embargo, por adherir al credo epidemiológico galiléico y cuantitativo, su ál gebra no se aparta mucho del perfil arriba anotado: Susser es famoso, en particular, por un libro no inocentemente denominado Causal thinking in the health sciences (1973) en donde la "secuencia del tiempo" (causa $\rightarrow$ efecto) propia de los eventos naturales se mantiene como el emento central en el análisis (p. 142). Por ello, porque el estudio del riesgo construido y evaluado en caliente por los humanos es "un campo minado", termina su texto con una confesión derrotista: "En epidemiología y ciencias sociales, la turbulencia, el voluntarismo y los bajos niveles de predicción son características manifiestas de los sujetos de estudio" (p. 162). Es una manera culta de repetir el dictamen del epidemiólogo despistado mencionado arriba, que hablaba del "problema" que creaban las irracionalidades humanas para el estudio de los riesgos.

La frase de Susser alude a un dominio que escapa a la caja de herrami entas descrita en la figura 1 en ésta lo más cercano a la situación concreta, a la grieta, al fuego, en que se construye el riesgo, son los métodos observacionales, aquellos que Durkheim defendía hace un sigl o como los únicos legítimos para la sociología. Esperamos haber mostrado, en los ejemplos, que el sentido subjetivo y mentado, la situación de intereses (Weber), 
la trama de significaciones (Geertz), el sentido del juego (Bourdieu) -es decir, el componente subjetivo como conjunto de tramasdebe entrar, también, en la constitución de la noción científica de riesgo: de otro modo no puede romperse la barrera de la intransitividad a que nos hemos referido varias veces.

Creemos, por tanto, que a los métodos experimentales y observacionales que se describen en la figura 1 deben añadirse, como complemento imprescindible, ciertos métodos para el estudio de las tramas que son constitutivas de los fenómenos humanos, pues el riesgo en materia de salud de que hemos venido habl ando hace parte de los fenómenos humanos, no simplemente naturales. En la figura 2 intentaremos mostrar, encerrándolo con una línea irregular, que hay un desdoblamiento, un estrato adicional de formas de estudio que no trabaja con bases seriadas -cuantitativas-, porque su objeto son las tramas de que hemos venido hablando, que no se cuentan ni se miden sino que se comprenden.

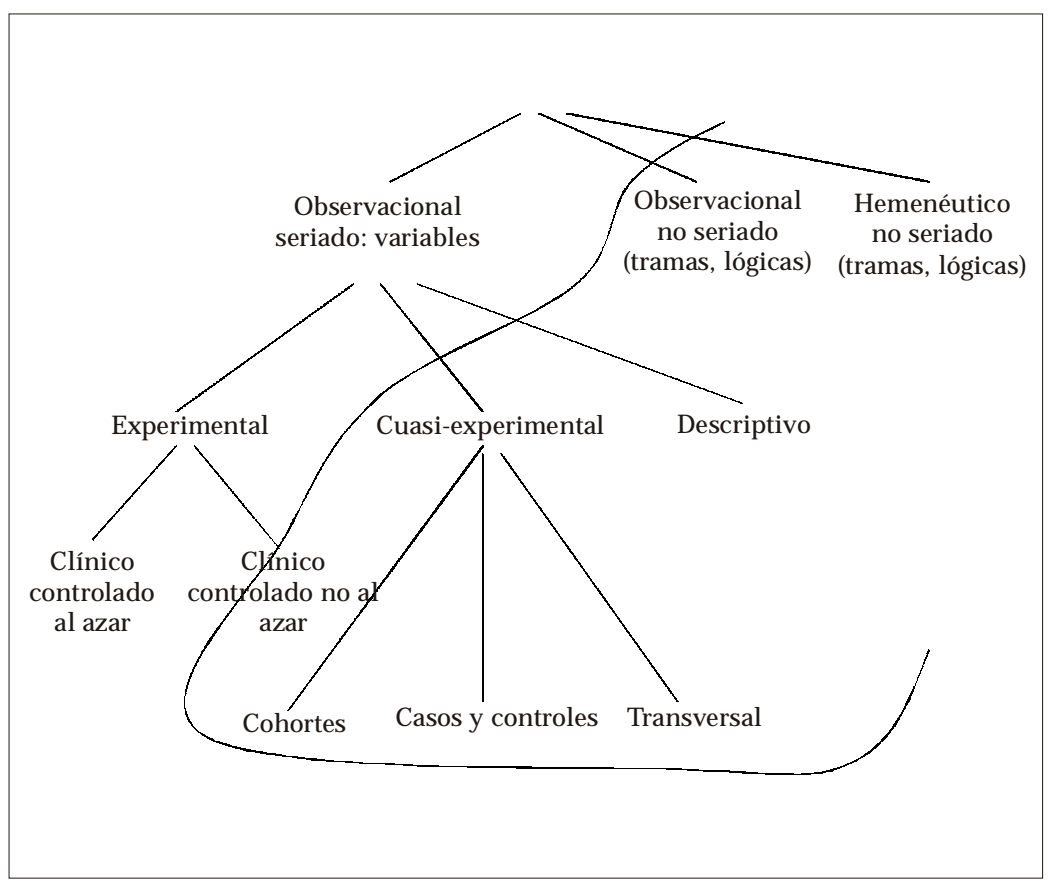


Hemos visto que hay toda una galería de tramas: institucionales o estructural es, tramas de sentido, de intereses y de eventos resultantes de ese juego de acciones humanas y naturales dentro de determinada situación. Estas últimas tramas de eventos son en términos objetivos las que determinan el riesgo de manera inmediata, y en su análisis estratificado pueden detectarse las tramas anteriores.

Sin duda, los epi demiól ogos más perspicaces han pensado el abanico de riesgos en situación arriba mencionado, de los cuales unos están en contravía de otros: deal guna manera, sus métodos multivariados apuntan en esta dirección, sobre todo ahora cuando comienzan a rendir frutos los avances de metodologías para estudios complejos, que combinan estrategias que se acercan a Ias cualitativas, como es el caso del Exploratory (Spatial) Data Analysis (Gelman, 2004; Lowe, 2003, cita un ejemplo referido al clásico tema de la distribución espacial de los riesgos).

Pero, que sepamos, en las versiones tradicionales de la epidemiología no se trabajan varios riesgos a la vez, ni menos, tramas de riesgos vistos desde la perspectiva subjetiva, en la forma descrita. Se trabajan varios "factores de riesgo", y "factores de prevención" al rededor de un riesgo. Los model os multivariados a lo sumo dan la lista de los "factores", Ies son asignados un peso numérico, positivo o negativo, dentro del conjunto, y luego son armados en la trama artificial de un modelo, construida por el investigador o el al goritmo del software. Estos "factores" son, como hemos dicho, atributos de las personas que tienen un riesgo específico sel eccionado y aislado como de interés epidemiológico -ejemplo, positividad al VIH, tabaquismo, infarto del miocardio, etcétera-.

En las formas clásicas de análisis epi demi ológico los atributos se recogen por encuesta -dial ógica u observacional-, que es la herrami enta apropiada para generar datos seriados; esos atributos se convierten luego en variables independientes mientras el riesgo, formulado como variable dicotómica, se convierte en variable dependiente. Las bases de datos así constituidas deben provenir de una muestra de $n$ adecuada -alta-, para que los métodos multivariados sean confiables. En las bases de datos las col umnas, que contienen las variables, se comparan unas con otras, en el esquema clásico en que hay una variable dependiente y una o más variables independientes. Los diseños 
buscan entonces generar "tramas" artificiales, es decir "modelos" en que se relacionan atributos -variables- con atributos, pero con dos características importantes: 1) los valores de las variables, que vienen en columnas, se aíslan de la fila a que pertenecen -cada fila es un caso- para poder "jugar en vertical" como columna. Cada variable es una serie de datos aislados de su caso, que pertenecen a n casos, y se trabaja por sí misma, independiente de las filas; y 2) Ios model os o "tramas" resultantes, es decir los esquemas rel acional es de variables así tratados, los genera el investigador, a mano y calculadora en las épocas heroicas previas al computador; hoy, ni siquiera segeneran sino que los "pide" el investigador, quien tiene a su disposición un paquete de opciones establecidas por los algoritmos del software. Así se generan los model os cuya validez ${ }^{15}$ se somete a valoración numérica, de orden probabilístico.

Consi deramos necesario decir una palabra incidental sobre las encuestas, observacionales o dialógicas, como herramienta exclusiva en el estudio epidemiológico. Hay en su uso exclusivo una confusi ón notable y general izada que procede de la propuesta cartesiana sobre el mundo natural, extenso, contable y medible, propuesta acogida por el empirismo lógico y que aún mantiene vigencia en al gunos rincones de las ciencias sociales, como si nada hubiera ocurrido a partir de Durkheim. Por extensión de las ciencias naturales, se cree que en las ciencias humanas la herramienta más apropiada, por ser "objetiva" y de base contable, es la encuesta seriada. Se aplica para todo; lo que no tiene esa base cuantitativa se considera de menor val or científico. Para quien conoce de tramas -institucionales, de sentido, de intereses y de acción- proceder así -sólo por encuesta- es como usar una raqueta de tenis en la función de remo porque se parece a un remo. Hay un hecho claro, las encuestas no sirven para comprender las tramas. Como relaciones que se dan en una situación, Ias tramas

15 No podemos entrar a discutir aquí la cuestión de la verdad, la verosimilitud, el ajuste o cualquier otro criterio de validez de los modelos científicos que representan o redescriben el mundo, sean ellos cuantitativos o cualitativos. Estamos inclinados a aceptar la propuesta de Giere (1988: 141 178) de que los científicos deciden mediante juicios complejos no puramente racionales, en donde la evidencia empírica - vista como similitud o analogía entre modelos y realidad- (p. 106) se combina con intereses no epistémicos. Este juicio o decisión sigue la línea propuesta por Herbert Simon de "modelos de decisión satisfactorios" (satisficing models), no modelos bayesianos en donde la probabilidad pura cumple su papel. Los seres humanos - dicen los cognitivistas de la línea de Giere-no son bayesianos sino satisfactores (satisficing) en sus decisiones prosaicas, y también en sus decisiones como científicos. Véanse Brown (2000) y Lipton (2000). 
sólo son accesibles a métodos que tengan en cuenta la situación de los casos concretos; esto quiere decir que debe tenerse en cuenta, por lectura horizontal de los casos, la información que aparece en las filas de la base de datos, y al go más: se necesita profundizar en cada caso para detectar las tramas en que se halla inserto. Esto no puede real izarse por medio de encuestas. La complejidad de este modo de operar hace que no puedan trabajarse muchos casos, sino pocos, y a veces uno que otro caso ejemplar.

Por tanto, en este otro modo de trabajo no se trata de construir artificialmente modelos a partir de combinación de variables, sino de descubrir esos modelos -tramas- tal como aparecen, ya construidos, por los seres humanos en la forma de instituciones, sentido, intereses y secuencia de eventos, y a partir del estudio y comprensión de esos casos singulares construir modelos más abstractos de carácter inferencial y explicativo. Este otro modo de trabajo comienza a perfilarse, desde el mismo campo de los estudios cuantitativos, o por lo menos teniéndolos en cuenta, en propuestas como las que revisa Abell (2004) en su recensión de las tendencias actuales en materia de la "explicación narrativa", como complementaria de la "explicación centrada en variables". Ya por lo menos se acepta que es posible trabajar "explicativamente" -diríamos, inferencialmente- con pocos casos y seguir el hilo narrativo en que se enmarcan los eventos humanos. Estos, como lo ha mostrado Paul Ricoeur (19831985), interpretando la mimesis aristotélica, tienen una configuración secuencial susceptible de ser trabajada por la mimesis narrativa.

Si se ha entendido bien la lógica de estas tramas construidas en vivo por los sujetos humanos -no por los investigadores- se comprenderá que el procedimiento de trabajar con columnas -variables- que desmembran los casos -representados en las filas- es útil pero hasta cierto punto y más allá de cierto punto: concretamente, para dar pistas sobre los model os cualitativos, y luego para verificar, atendiendo a unos cuantos marcadores establecidos en los model os hi potéticos, la distribución extensa de I os casos análogos, a los que se aplicaría el modelo, en un espacio social o geográfico.

Cuando se trata de captar las tramas mismas construidas en las situaciones, hay que mirar cada caso en su situación concreta, porquees allí en dondese encuentran definidos los riesgos 
vivos, puestos - para seguir a Borges- en la grieta. Se trata en realidad de tramas, teji dos densos desenti do y deintereses, casi siempre institucional izadas, que definen en últimas las tramas de eventos concretos que causan el daño en cuestión.

Así, por ejemplo, se trabaja el riesgo de adquirir el VIH que tienen las trabajadoras sexual es someti das a la campaña del condón $100 \%$, como también el de los jóvenes backpackers ávidos de experiencias extremas, y el de las jóvenes que acompañan a sus novios que no entregaron las Ilaves de su auto. Sus evaluaciones subjetivas definen el peso del riesgo que corren, cuando lo insertan en el complejísimo tejido de opciones -todas más o menos riesgosas- que tienen ante sí. Y, lo más grave, esas evaluaciones subjetivas no siempre se corresponden con el riesgo objetivo, que depende a veces de fuerzas que están más allá de su propio control, incluso, más allá o acá del orden simbólico en que se desenvuelven sus subjetividades. Como dijimos antes, una bala o un virus no responden a juegos humanos de intereses, son ciegos a los valores simbólicos, pero vienen empaquetados en esos juegos simbólicos que hacen los humanos.

La comprensión de estas tramas -institucional es, de sentido, de intereses y de eventos- se lograría, en primer lugar, a partir de métodos observacionales de base no seriada -encuesta- sino etnográfica -narrativa-. Es importanteinsistir quea veces un buen caso bien estudiado ilumina más sobre las tramas que mil casos desmembrados en valores leídos en vertical, es decir, que prescinden de las tramas que se construyen en las situaciones objetivas. Estos diseños observacionales, usual es en etnografía, podrían, posiblemente, clasificarse en forma anál oga a como se clasifican los métodos observacionales de carácter seriado, cuantitativo, quese presentaron en la figura 1 La figura 2 muestra una primera hipótesis del desdoblamiento y clasificación de estos diseños cualitativos. Se establece así un segundo estrato de formas de trabajo que tiene valor heurístico, para comenzar una caracterización que puede ser mucho más compleja.

El complemento necesario de los métodos observacionales cual itativos encerrados con la curva irregular de la figura 2 serían los métodos hermenéuticos que trabajan las tramas de significaciones, que proceden del horizonte interno de los sujetos de campo y están plasmadas en el lenguaje oral y escrito o el para-lenguaje con que, sin palabras, ocasi onal mente se comunican los seres humanos. 
Arriba se habló de que para comprender las tramas en ocasiones una sol a instancia singular resul ta mucho más el ocuente que un conjunto de variables recogi das por mil encuestas. Allí, en esa instancia singular situacional, o en una serie manejablees decir pequeña- de instancias situacionales, el investigador, usand o toda la gama disponi ble de métodos que la ingeni osidad especial izada ha perfilado, logra captar la lógica subyacente, que permite dar cuenta de esa(s) instancia(s) singular(es), y ... de otras análogas. Esta inferencia -"generalización", dirían otroses importante. Uno no puede quedarse en el caso singular, así lo haya explicado o comprendido a cabalidad: debe hacer "ciencia", el evarseal conocimiento general , aplicableal caso origi nal y a sus análogos.

En efecto, en este modo deindagar hay una lógi ca inferencial en donde es central "el demonio de la analogía" de que habla Bourdieu en el Sentido práctico (1980b). Esta lógica pertenece a una tradición diferente de la gali leana deque hablaba Ginzburg y que está en el núcleo de los métodos tradicional es epidemiológicos. Dar cuenta de casos singulares es hacer estudios ad hoc, y no científicos, porque la ciencia debe construir, a partir de esas singularidades, model os abstractos que den cuenta de los casos que sirvieron de ejemplo, pero de al go más: de los posibles casos que comparten con los singulares ya estudiados un conjunto de rasgos que comparte con ellos en virtud de la analogía. Así se comprende la famosa frase de Geertz (1995 33) que sostiene que los antropólogos no estudian aldeas, sino en aldeas.

Como dijimos, esa lógica otra, de carácter abductivo, ha sido estudiada a partir de los ejemplos prácticos de los detectives de ficción y de las bases filosóficas postuladas por C. S. Peirce; hoy comienza a ser tratada con rigor en los medios profesionales de la ciencia o fil osofía de la ciencia (por ejemplo, Magnani, 2001; véase Lipton, 2000). Vale la pena recordar que también en el campo de la jurisprudencia aparece una vena abductiva importante, que también trabaja la inferencia a partir "del razonamiento ejemplar por analogía" (Brewer, 1996); igualmente es posi ble esperar que la revisión a fondo de los métodos etnográficos conocidos como "thick and thin" y como "multisited ethnography" produzcan nuevos modos de tratar adecuadamente estos objetos de estudio (Marcus, 1998). En estos modos de trabajo cualitativo los casos no se desmembran en variables sino 


\section{Revista Colombiana \\ de Antropología \\ Volumen 40, enero-diciembre 2004

que se toman por sí mismos, en la complejidad manejable que permiten los métodos etnográficos, los viejos y los nuevos.

Este modo de trabajo indicial-abductivo procede con presupuestos y técnicas que para nada se apoyan en la serie, y menos en el tamaño reducido del error estándar -y de las muestras grandes- que, como se sabe, contribuye a la fórmula del margen de error, usual en las inferencias cuantitativas. El muestreo para trabajo con tramas va por otros rumbos y puede, en ciertos casos privilegiados, basarse en una sola instancia ejemplar, si es adecuada, es decir si su riqueza empírica es tal que permite captar la lógica profunda, y prototípica, de la trama de la acción, que subyace a las, aparentemente variadas, situaciones de riesgo.

El ascenso desde la situación singular, histórico-biográfica, que implica una trama de riesgos -obsérvese que se habla de situación, no de individuo- hasta una situación prototípica o modélica, opera con lógi cas de inferencia que son tradicional es en antropología, por lo menos desde cuando se plantearon las bases de lo que se llama el método de comparación controlada (Sartori y Morlino, 1994).

Hay otras tradiciones epistemológicas para este ascenso inferencial que son igual mente importantes. La más famosa tiene ancestro hegeliano, está inscrita en la obra de Marx, y ha sido trabajada por al gunos autores. Se denomina el ascenso desdeel singular concreto hasta el universal concreto. No nos detendremos aquí en este aspecto técnico y epistemológico que ya hemos tratado en otra ocasión (Sevilla, 2003) y hoy es objeto de discusión, aunque no necesariamente con este nombre -se habla de criterios de validación, de interpretación, de representación-, en los tratados que dan visiones panorámicas de la “investigación cualitativa” (ejemplo: Smith y Deemer, 2002).

Interesa decir que esta relación entre el singular concreto y el universal concreto es también aspecto de interés para otro modo "especial izado" completamente diferente del modo científico de conocer -el modo artístico de modelar (mejor, metaforizar)- la real idad. Bourdieu en sus Reglas del arte (1980a: 453458) tiene unas pocas páginas síntesis en donde resume sus ideas sobre los dos modos de "illusio", que contrastan con el modo fundamental del conocimi ento ordinario, el del sentido común; habla de la illusio de la ciencia -sociológica- y de la del arte -literario-. 
La diferencia entre las artes y las ciencias, entre los model os y las metáforas como representaciones elaboradas del mundo en que vivimos o somos, no es tanta como tradicional mente se ha pensado. En ello coincide Bourdieu con el último Paul Feyerabend (1999: 223241); de ell o nos convence también Borges -esperamos haberl o mostrado-, quien con su bella metáfora nos introdujo en la presente reflexión sobre las álgebras del riesgo. Arte y ciencia -literatura y sociología/antropología- han sido equiparadas también por un autor del campo antropológico, Clifford Geertz (1994: 5-72), quien dice que ambos son modos distintos de llegar a un mismo objetivo, hacer que lo muy cercano, las situaciones concretas, muestren sin embargo lo profundamente distante, es decir la generalidad humana.

El paral elo ciencia y arte no es gratuito en el presente contexto. Lo traemos, expresamente, porque con respecto a las artes, no sólo literarias, sino, y sobre todo, plásticas, se han hecho planteamientos importantes para entender la lógica inferencial, no cuantitativa, que relaciona lo singular concreto con lo universal concreto (Whimsatt, 1954) ${ }^{16}$. Nel son Goodman, en su Language of art (1968) y obras posteriores $(1978,1984)$ ha trabajado de manera sistemática la justificación de la instancia o caso ejemplar. El ejemplo -la "muestra" del muestrario del sastre- es un

16. Un tratamiento más detallado del paralelo entre investigación en ciencia y creación artística puede verse en E. Sevilla (2004). modo de la referencia o simbolización, que vincula los símbolos lingüísticos o icónicos -nuestras ál gebras- con las cosas del mundo. La ejemplarización, según Goodman, va de lo singular a lo abstracto, a la inversa de la denotación, y cumple funciones importantes en los procesos cognitivos, concretamente en la generación de modelos/metáforas que son versiones del mundo. El caso ejemplar, la muestra del muestrario, podría convertirse, en la antropología del riesgo, en la contraparte de la muestra seriada representativa de la epidemi ol ogía del riesgo. Esta epistemol ogía de Goodman permite explicar, ante los ojos incrédulos de los que operan con la lógica inductiva que está detrás de los modelos seriados -cuantitativos-, que es legítimo y posible inferir a modelos abstractos/concretos -universal es concretosa partir de un puñado de instancias singulares, sin pasar por los trámites de probabilidades e interval os de confianza. Al fin y al cabo, se trata de otra lógica, de otro modo de pensar, radicalmente basado en la anal ogía. 
En la figura 2 se ha hecho el intento de separar con una línea curva irregular el estrato superpuesto de estudios empíricos cual itativos que podrían estar cubiertos por este otro modo deinferir en la antropol ogía del riesgo. Hay autores (ejemplo, Bernard, 1995) que ya han hecho intentos -todavía dentro del modo de pensar lógicoempirista y de hegemonía cuantitativa- de sistematizar los modos de trabajo inferencial en antropología, aprovechando el importante avance logrado por los especial istas en model os cuantitativos, experimentales y cuasi-experimentales -sociólogos, psicólogos, epidemiólogos- en cuanto a especificación de tipos de estudio en ciencias humanas. Puedepensarsequeestos tipos, así delimitados, pueden ser aprovechados, operando con la otra lógica -la indicial y abductiva- por lo menos para iniciar un diálogo en la mesa que acoge a cuantitativistas, por un lado, y a abductivistas/indiciales por el otro. No es la ocasión de entrar en los detalles de estos intercambios especializados, que deben partir de las propuestas sólidas que desde hace años tenemos en la obra de Campbell y Stanley (1966) y de Cook y Campbell (1979) y que últimamente han hallado acogida en las concepciones recientes que se alinean con Ios planteamientos cognitivos y naturalistas de una futura ciencia de las ciencias, distinta de la tradicional filosofía de la ciencia que ha estado, y todavía persiste en al gunos rincones, bajo la hegemonía del empirismo lógico (Giere, 1988, 1992, 2000).

\section{CONCLUSIÓN: EL RIESGO POSITIVO DE CONSTRUIR CONOCIMIENTO}

\footnotetext{
P ARA CONCLUIR, ES IMPORTANTE MANTENER LA IDEA DE QUE LOS VArios modos de trabajo, los observacionales y los hermenéuticos, los cuantitativos y los cual itativos, son necesarios para el tratamiento integral del asunto del riesgo. Lo decimos porque se ha observado cierta tendencia reciente a excluir los métodos experimental es y cuasi-experimentales de la caja de herramientas no sólo de la sociología y antropología sino también de la emergente epi demi ol ogía social , con el argumento de sus limitaciones. Al contrario, como bien lo sugiere Berkman (2004) el propósito de mirar el bosque no debe impedir el complementario de mirar los árboles individuales. El hecho de que mostremos las limitaciones de los modos cuantitativos tradicionales de estudiar
} 
el riesgo no supone que despreciemos sus potencialidades, que son muchas y admi rables. Desconocerl os no autoriza a despreciarIos, y conocerlos permite que el trabajo se haga de manera equilibrada, contando y midiendo lo que es contable y medible en los asuntos humanos. Estedesconocimiento puedeimplicar queno se atiendan desarrollos muy interesantes que parecen converger, desde lo cuantitativo y lo cual itativo, hacia el tratamiento combinado de situaciones complejas, como lo que parece está ocurriendo con los métodos emergentes, como los mencionados Exploratory (Spatial) Data Analysis, y la explicación narrativa.

Hemos querido plantear en el presente artículo el reto de la cooperación al rededor de los modos de estudiar el riesgo en términos muy precisos, y acaso técnicos, con la esperanza de que se inicien los diálogos entre los representantes de los varios modos de tratarlo. Al hacerlo corremos riesgos -negativos- de malentendidos, pero también -positivos- de romper con décadas de "desatención benigna" entre grupos de estudiosos bien intencionados. Es preciso avanzar haciendo cami nos por la enormeselva de conocimientos por crear, y de los modos nuevos de crearlos, que apenas hemos bosquejado en la figura 2. Sól o mediante proyectos singulares ejemplares podremos llevar a la práctica el diseño de estos nuevos modos cooperativos, quea su vez permitirán construir nuevos caminos.

\section{REFERENCIAS BIBLIOGRÁfICAS}

AвelL, P. 2004. "Narrative explanation: An alternative to variable centered explanation". Annual Review of Sociology. 30.

Alonso, P., J. Sacarlal, J. J. Aponte, A. Leach et al. 2004. "Efficacy of the RTS,S/AS02A vaccine against Plasmodium falciparum infection and disease in young African children: Randomised controlled trial". The Lancet. 364 (9443).

Beck, U., A. Giddens y S. LAsH. 2001 Modernización reflexiva: política, tradición y estética en el orden social moderno. Alianza Editorial. Barcelona.

Berkman, L. F. 2004. "Introduction: Seeing the forest and the trees: from observation to experiments in social epidemiology". Epidemiologic Reviews. 26. 
BeRnARD, H. R. 1995 Anthropological research methods: Quantitative and qualitative approaches. Altamira Press. Walnut Creek.

Bhrolchain, M. N. 2001 “'Divorce effects' and causality in the social sciences". European Sociological Review. 17 (1).

Borges, J. L. [1949] 1974. “Nathaniel Hawthorne”. Obras completas. Emecé Editores. Buenos Aires.

Bourdieu, P. 1980a. Les règles de l'art: genèse et structure de champ littéraire. Éditions du Seuil. París. 1980b. Le sens pratique. Les Éditions Minuit. París.

BREWER, S. 1996. "Semantics, pragmatics and the reasonal force of legal argument by analogy". Harvard Law Review. 109.

Brown, H. I. 2000. "Judgement, role in science". En W. H. NewtonSmith (ed). A companion to the philosophy of science. Oxford University Press. Oxford.

Bucalla, C. M. y V. Palma. 2002. “Da compreensão da vulnerabilidade social ao enfoque multidisciplinar. From understanding social vulnerability to a multidisciplinar outlook". Revista de Saúde Pública. 3 (4) Supl.

CAILlois, R. 1986. Los juegos y los hombres: la máscara y el vértigo. Fondo de Cultura Económica. México.

Campbell, D. T. y J. C. Stanley. 1966. Experimental and quasi-experimental designs. Rand McNally. Chicago.

Cook, T. D. y D. T. CAmpBell. 1979. Quasi-experimentation: Design and analysis issues for field settings. Rand McNally. Chicago.

CutTer, S. L. 2003 "Vulnerability of science and the science of vulnerability". Annals of the Association of American Geographers. 98(1).

DANTIER, B. 2003 “La chose sociologique et sa représentation: introduction aux règles de la méthode sociologique d'Émile Durkheim". http:// www.uqac.uquebec.ca/zone30/Classiques_des_sciences_sociales/ index.html

Delor, F. y M. Hubert. 2000. "Rethinking the concept of vulnerability". Social Science and Medicine. 50.

Denzin, N. K. E Y. Lincoln (eds.). 2000. Handbook of qualitative research. Sage Publications. Thousand Oaks.

Douglas, M. 1966. Purity and danger: An analysis of conception of polution and taboo. Routledge and Kegan Paul. Londres.

---_-----. 1986a. How institutions think. Syracuse University Press. Syracuse, NY.

1986b. Risk acceptability according to the social sciences. Russel-Sage Foundation. Thousand Oaks. 


\section{Londres.}

1992. Risk and blame: Essays in cultural theory. Routledge.

DouglAS, M. y A. WILDAVSKY. 1982. Risk and culture. California University Press. Berkeley.

Durkheim, E. [1895] 1987. Les règles de la méthode sociologique. Presses Universitaires de France. París.

Duvignaud, J. 1980. Le jeu du jeu. Baland. París.

Eco, U. y T. Shebeok (eds.). 1989. El signo de los tres: Dupin, Holmes, Peirce. Editorial Lumen. Barcel ona.

ELSTER, J. 1989. Ulises y las sirenas: estudios sobre racionalidad e irracionalidad. Fondo de Cultura Económica. México.

FeE, E. y N. KRIEGer. 1993 “Understanding AIDS: Historical interpretations and the limits of biomedical individualism". American Journal of Public Health. 83

Feyerabend, P. 1999. Conquest of abundance: A tale of abstraction versus the richness of being. Edited by Bert Terpstra. The University of Chicago Press. Chicago.

Foucault, M. 1966. El nacimiento de la clínica: una arqueología de la mirada médica. Siglo XXI Editores. México.

GeerTz, C. 1994. Conocimiento local: ensayos sobre la interpretación de las culturas. Paidós I bérica. Barcelona.

1995 La interpretación de las culturas. Gedisa. Barcelona.

Gelman, A. 2004. "Exploratory data analysis for complex models". Journal of Computational and Graphical Statistics. 13(4).

Giere, R. N. 1988. Explaining science: A cognitive approach. University of Chicago Press. Chicago.

1992. Cognitive models of science (Minnesota Studies in the Philosophy of Science. Vol. 15). University of Minnesota Press. St. Paul.

2000. "Cognitive approaches to science". En W. H. NewtonSmith (ed.). A companion to the philosophy of science. Oxford University Press. Oxford.

GinZBURG, C. 1994. "Indicios: raíces de un paradigma de inferencias indiciales". En Mitos, emblemas, indicios: morfología e historia. Gedisa. Barcel ona.

Goodman, N. 1968. Languages of art. The Bobbs-Merrill Co. Nueva York. York. 1978. Ways of worldmaking. Hackett Publishing Co. Nueva 1984. Of mind and other matters. Harvard University Press. Cambridge, Mass. 
Graves, P. y H. Gelbhand. 2004. "Vaccines for preventing malaria”. (Cochrane Review). http://www.mediscope.ch/cochrane-abstracts/ ab000129.htm. Consultado el 30 de septiembre de 2004.

Grimes, D. y K. F. Shulz. 2002. "An overview of clinical research: The lay of the land". The Lancet. Epidemiologic Series. 359.

HaBermAS, J. 1971 Knowledge and human interest. Beacon Press. Boston.

Harrison, C. 1978. Mosquitoes, Malaria and man: A history of the hostilities since 1880. E. P. Dutton. Nueva York.

Homedes, N. y A. UGALDE. 2001 "Improving the use of pharmaceuticals through patient and community level interventions". Social Science and Medicine. 5 .

Humphreys, P. 2000. "Causation". En W. H. Newton Smith (ed.). A companion to the philosophy of science. Oxford University Press. Oxford.

JefrReY, C. M. 1976 "Malaria control in the twentieth century". American Journal of Tropical Medicine and Hygiene. 25

KALIPENI, E. 2002. "Health and disease in Southern Africa: A comparative and vulnerability perspective". Social Science and Medicine. 50.

Karmiloff-Smith, A. 1992. Beyond modularity. Themit Press. Cambridge, Mass.

KAWACHI, S. S. V. 2004. "Income inequality and health: What have we learned so far?". Epidemiologic Reviews. 26.

Koopman, J. S. 1996. "Emerging objectives and methods in epidemiology". American Journal of Public Health. 86.

Koтtow, M. 2003 "The vulnerable and the susceptible". Bioethics. 7 (56).

LIPTON, P. 2000. "Inference to the best explanation". En W. H. NewtonSmith (ed.). A companion to the philosophy of science. Oxford University Press. Oxford.

Litsios, S. 2001 Plague legends I: From the miasmas of Hippocrates to the microbes of Pasteur. Science and Humanities Press. Chesterfield.

LoWE, J. W. 2003 “Emerging tools and concepts of exploratory spatial data analysis". Geospatial Solutions. 13(7).

LUPTON, D. 1999. Risk. Routledge. Londres.

Lupton, D. y J. TULLoCH. 2002a. “'Risk is part of your life': risk epistemologies among a group of australians". Sociology. 36 (2).

------. 2002b. “'Life would be pretty dull without risk': Voluntary risk taking and its pleasures". Health, Risk \& Society. 4 (2).

MacMahon, B. y T. F. Pugh. 1970. Epidemiology: Principles and methods. Little Brown. Boston. 
MAGNANI, L. 2001 Abduction, reason, and science: Processes of discovery and explanation. Kluwer Academic/Plenum Publishers. Nueva York.

Marcus, G. E. 1998. Ethnography through thick and thin. Princeton University Press. Princeton.

Marinı, M. y B. Singer. 1988. "Causality in the social sciences". Sociological Methodology. 18.

Miller, E. P. 2003 "Bodies and the power of vulnerability". Philosophy Today. 46(5).

MISAK, C. 2000. "Peirce". En W. H. Newton-Smith (ed.). A companion to the philosophy of science. Oxford University Press. Oxford.

MYKHALOVSKIY, E. Y L. WeIR. 2004. "The problem of evidence-based medicine: Directions for social science". Social Science and Medicine. 59 (5).

Newton-Smith, W. H. 2000. "Explanation". En W. H. Newton-Smith (ed.). A companion to the philosophy of science. Oxford University Press. Oxford.

Organización Panamericana de la Salud. 1986. Manual sobre el enfoque de riesgo en la atención materno infantil. OMS/OPS. Serie Paltex. Washington.

OsoRIO, L. 2003 "Effects of population mobility on Malaria morbidity in an urban area in Colombia". PhD Thesis. University of London.

Oxford Center Ebm. 2004. http://www.cebm.net/. Consultado el 30 de septiembre de 2004.

PACKARD, R. M. 1984. "Maize, cattle and mosquitoes: The political economy of Malaria epidemics in colonial Zwaziland". Journal of African History. 25(2).

PalACIOS-FRAIRE, S. 1975 "Analysis of the principal problems impeding normal development of Malaria eradication programs". Bulletin of the Panamerican Health Organization. 9 (4).

PALMER, C. 2002. “'Shit happens': The selling of risk in extreme sport". The Australian Journal of Anthropology. 13(3).

PARKER, R. 2001 "Sexuality, culture and power in HIV/AIDS research". Annual Review of Anthropology. 30.

PearL, J. 2004. "The art and science of causal effect" including outline of "algebra of Doing". http://bayes.cs.ucla.edu/Lecture/lecture_sec2.htm Consultado el $\mathbf{1 0}$ de septiembre de 2004.

PInKER, S. 1997. How the mind works. Norton. Nueva York.

Poundstone, K. E., S. A. Strathdee y D. D. Celentano. 2004. “The social epidemiology of Human Inmunodeficiency Virus/Acquired Inmunodeficiency Syndrome". Epidemiologic Reviews. 26. 
Quevedo, N. 2004. "Las cuentas de Patarroyo". El Espectador. Bogotá. 29 de mayo de 2004.

Richie, T. L. y A. SAUL. 2002. "Progress and challenges for Malaria vaccines". Nature. 415

Rıcoeur, P. 19831985 Temps et récit. Vols. 1, 2, 3 Éditions du Seuil. París.

Rose, G. 1985 “Sick individuals and sick populations". International Journal of Epidemiology. 14.

---------. 1992. The Strategy of preventive medicine. Oxford University Press. Oxford.

Rothman, K. J. 2002. Epidemiology: An introduction. Oxford University Press. Nueva York.

SARtoRI, G. y L. Morlino (eds.). 1994. La comparación en las ciencias sociales. Alianza Editorial. Madrid.

SCAL, P., M. IrelAND E I. W. BorowsKY. 2003 "Smoking among American adolescents: A risk and protective factor analysis". Journal of Community Health. 28 (2).

SchoEPF, B. G. 2001 "International AIDS research and anthropology: Taking a critical perspective on the crisis". Annual Review of Anthropology. 30.

Searle, J. Intentionality: An essay in the philosophy of mind. Cambridge University Press. Nueva York.

SeVILLA, E. 1989. "Mal aria and anthropol ogy: Towards a treatment of mal aric communities as human ecosystems". Trabajo final preparado durante estadía en el departamento de bioestadística y epidemiología de la Universidad de Tulane, New Orleans, y preparado para el programa TDR de la OMS. Cidse, Universidad del Valle. Cali.

1998 "Modelos analíticos de las ciencias sociales para prevención de infección por VIH". En E. Sevilla (ed.). Cinco estudios antropológicos sobre el mal de amores en la ciudad de Cali. Documento de Trabajo 44. Cidse, Universidad del Valle. Cali.

2003 "Hacer etnografía de amores". En E. Sevilla et al. El espejo roto: ensayos antropológicos sobre los amores y la condición femenina en la ciudad de Cali. Fondo Editorial de la Universidad del Valle. Cali.

----. 2004. "Modos y niveles de investigación en artes: comentarios desde la antropología". Revista EntreArtes (Universidad del Valle, facultad de artes intregradas). 3

1994 (con K. V. Feliciano y J. Olaya). “Dueños de sí y de sus deseos: estudio sobre la sexualidad de los colombianos y su vulnerabilidad al VIH. Informe de análisis antropológico de una 
encuesta nacional realizada por el ISS/Profamilia". Cidse, Facultad de Ciencias Sociales y Económicas. Cali. Documento en CD.

SevilLa, E. 1997 (con A. Martínez). "Observaciones desde Cali, Colombia, sobre lógi cas prácticas de barrera e intimidad en el uso del condón en el comercio sexual femenino". En E. Sevilla et al . Erotismo y racionalidad en la ciudad de Cali: informe científico del proyecto Razón y sexualidad. Fase 1 Documentos de Trabajo. 32. Cidse, Universidad del Valle. Cali.

2003(con A. Machado). “De 'putas' y 'prostitutas' a 'fufurufas', 'diablas' y 'bandidas'". En E. Sevilla et al. El espejo roto: ensayos antropológicos sobre los amores y la condición femenina en la ciudad de Cali. Fondo Editorial de la Universidad del Valle. Cali.

Simon, W y J. H. Gagnon. 1986. "Sexual scripts: Permanence and change". Archives of Sexual Behaviour. 15(2).

Smith, J. K. y D. K. Deemer. 2002. "The problem of criteria in the age of relativism". En H. K. Denzin e I. Lincoln (eds.). Handbook of qualitative research. Sage Publications. Thousand Oaks.

Susser, M. W. 1973 Causal thinking in the health sciences: Concepts and strategies of epidemiology. Oxford University Press. Nueva York.

Susser, M. W., W. Watson y K. Hopper. 1985 Sociology in medicine. Oxford University Press. Nueva York.

Trostle, J. A. y J. Sommerfeld. 1996. "Medical anthropology and epidemiology". Annual Review of Anthropology. 15

Unaids, United National Programme on Hiv/Aids/World Health Organization (WHO). 2003. AIDS epidemic update: 2003 WHO Publication No. UNAIDS/0339E. Ginebra.

Van de Perre, P. y J. P. Dedet. 2004. "Vaccine efficacy: Winning a battle (not war) against malaria". The Lancet. 364 (9443).

VARGAS, V. M. 2004. "Científico que desarrolló vacuna efectiva contra malaria cree que se puede derrotar la enfermedad". El Tiempo. Bogotá. 24 de octubre.

Weber, M. 1944. Economía y sociedad. Fondo de Cultura Económica. México.

WeISS, U. 2002. "Foreword". Insight, Malaria. Nature. 415

Williams, C., V. Chuprov y J. Zubok. 2003 "Risk and modernity: Theories and concepts". En Youth, risk and Russian modernity. Hampshire, UK. Ashgate.

WHIMSATT, W. K. 1954. "The structure of the concrete universal". En D. Keesey (ed.). Contexts for criticism. Mayfield Publishing Company. Toronto. 